\title{
UNA MIRADA CONTEMPORÁNEA \\ A LA REVISIÓN DEL CONTRATO \\ DE SUMINISTRO ELÉCTRICO \\ ANTE EVENTOS IMPREVISTOS
}

\section{A CONTEMPORARY PERSPECTIVE IN THE REVISION OF POWER PURCHASE AGREEMENT IN LIGHT OF UNFORESEEN CIRCUMSTANCES}

Karl Conrads Araya*

Carlos Berner Zúñiga**

\section{Resumen}

En este trabajo analizaremos el comportamiento intrínsicamente variable e imprevisto del mercado eléctrico chileno con relación a los contratos de suministro eléctrico, haciendo hincapié en la transformación que ha causado la entrada masiva de energías renovables no convencionales desde el año 2015. En este sentido, al alero de la teoría de la imprevisión y de las cláusulas de ajuste o revisión de precios, estudiaremos las posibilidades que tienen las partes contratantes de reajustar sus pactos conforme a las nuevas circunstancias sobrevinientes a su celebración.

Palabras claves: mercado eléctrico; contratos de suministro eléctrico; teoría de la imprevisión; cláusulas hardship.

\section{AbStRact}

In this article, we analyze the intrinsically variable and unforeseen behavior of the Chilean electricity market regarding power purchase agree-

* Abogado en Ugarte \& Correa. Código postal: 7550692. Correo electrónico: kconrads@ugartecorrea.com

** Abogado en Vergara, Labarca \& Cía. Código postal: 7630000. Correo electrónico: cberner@vl.cl.

Artículo recibido el 16 de septiembre de 2019 y aceptado para su publicación el 10 de noviembre de 2019 . 
ments, emphasizing the transformation caused by the massive influx of non-conventional renewable energies since 2015. In this vein, on behalf of the unforeseen events theory and price adjustment or revision clauses, we study the parties possibilities to readjust their agreements in light of the new circumstances that arise after its conclusion.

Key words: electricity market; power purchase agreements; unforeseen events theory; hardship clauses.

\section{CONSIDERACIONES PRELIMINARES}

En los últimos años, el mercado eléctrico nacional ha experimentado una transformación radical: Chile se ha transformado en un "pulmón verde" debido a la entrada masiva de ERNC de distinto tipo, principalmente plantas eólicas, solares y geotérmicas. Esto ha permitido diversificar la competencia incorporando dentro de la matriz eléctrica una extraordinaria cantidad de energía limpia, al punto que a fines del año 2018 se llegó a suministrar el 20\% del consumo eléctrico a través de fuentes ERNC -tal como estaba previsto ser cumplido recién hacia el año 2025 por la Ley

10 n. ${ }^{\circ} 20698-$ y a fines de 2019 se contaba con una capacidad de generación instalada de aproximadamente $5300 \mathrm{MW}^{1}$. Este espectacular crecimiento le significó a Chile ser reconocido en el informe "Climatescope 2018", preparado por la prestigiosa consultora Bloomberg NEF, como el país en vías de desarrollo - de una lista de ciento tres países- con mejores alternativas para la realización de proyectos ERNC ${ }^{2}$.

Pero el reto es aún mayor. Las políticas del Ministerio de Energía, respaldadas en una enorme cantidad de proyectos "verdes" ya aprobados $\mathrm{y}$ en los resultados de las últimas licitaciones de suministro para clientes regulados, buscan seguir consolidando este crecimiento con una meta desafiante: lograr que al año 2050, al menos un 70\% del suministro eléctrico

${ }^{1}$ Disponible en www.revistaei.cl/2019/12/23/energias-renovables-cerraran-2019-conmas-de-5-300-mw-de-proyectos-en-operaciones/ [fecha de consulta: 26 de diciembre de 2019].

${ }^{2} \mathrm{El}$ estudio ponderó la calificación de cada país en tres áreas: fundamentals, opportunities y experience. Bloomberg Nef (2018).

El correlato en el ámbito de las inversiones es igual de gráfico: de tan solo cien millones de dólares invertidos en ERNC el año 2011, la cifra aumentó a tres coma cinco billones de dólares para el año 2015. Bloomberg Nef (2018), p. 59.

En el informe "Climatescope 2019", Chile volvió a ser destacado ocupando la segunda posición en el ránking. Disponible en http://global-climatescope.org/assets/data/reports/ climatescope-2019-report-en.pdf [fecha de consulta: 3 de marzo de 2020]. 
sea proveído por fuentes $\mathrm{ERNC}^{3}$. Recientemente, el Ministerio, incluso, adelantó la meta para el año $2030^{4}$.

Sin perjuicio de que el escenario descrito sea muy auspicioso, la transición de un modelo energético convencional a uno ERNC supone superar desafíos sociales y jurídicos no menores, para cuyo éxito se requiere de una sinergia entre intereses públicos y privados. Entre estos últimos, esta reciente transformación del mercado eléctrico vuelve a recordarnos una característica inherente del mismo: su gran volatilidad frente a usuales cambios coyunturales o estructurales, cuestión que colisiona con la estabilidad que las partes buscan asegurar cuando suscriben contratos de suministro de energía eléctrica, especialmente, de largo plazo, ocasionando desequilibrios contractuales imprevisibles a la época de su celebración.

En este sentido, revisaremos los principales cambios ocurridos en el mercado eléctrico con relación a la entrada masiva de ERNC que se ha propiciado en el último tiempo, dando cuenta de cómo este fenómeno puede abrir una ventana a la inclusión de prácticas más sofisticadas de redacción de cláusulas de ajuste o revisión de precio, de modo de anular o morigerar los efectos que circunstancias imprevistas puedan ocasionar en contratos de suministro. Como veremos, la falta de consenso doctrinario y jurisprudencial sobre la teoría de la imprevisión hace aún más deseable el desarrollo e implementación de este tipo de cláusulas.

\section{NOCIONES BÁSICAS}

DEL FUNCIONAMIENTO DEL MERCADO ELÉCTRICO

Entender cómo funciona el mercado eléctrico no es una tarea fácil, sobre todo considerando que se compone de un entramado regulatorio que convive con el desarrollo de la libre actividad económica. Sin embargo, es necesario exponer las reglas básicas de su funcionamiento, sobre todo del segmento de generación eléctrica, para comprender las controversias jurídicas que afectan a los contratos de suministro de energía eléctrica PPA -como se conocen en inglés-.

A partir de la década de 1980, con la fijación del texto refundido de la LGSE de 1982, se instauraron los principios rectores del mercado eléctrico chileno. Bajo un esquema descentralizado, se distinguieron, por un lado,

${ }^{3}$ Ministerio de Energía, Política Energética 2050. Disponible en www.energia.gob.cl/ sites/default/files/energia_2050_-_politica_energetica_de_chile.pdf [fecha de consulta: 12 de agosto de 2019].

${ }^{4}$ Disponible en www.emol.com/noticias/Tecnologia/2019/12/10/969926/Meta-70energias-renovables-COP25.html [fecha de consulta: 1 de marzo de 2020]. 
las actividades de distribución y transmisión -las que, por verificar características de monopolios naturales, se sujetan a un modelo de regulación de precios- $y$, por otro, la actividad de generación, esta última según un modelo de libre mercado ${ }^{5}$.

Como en todo mercado, en la comercialización de la energía participan oferentes y demandantes. Los oferentes están constituidos por empresas de generación eléctrica, mientras que los demandantes se subdividen en dos categorías: clientes libres -usuarios con potencia conectada superior a $5000 \mathrm{KW}$, grandes clientes industriales compañías mineras-, los cuales negocian y pactan libremente contratos de suministro con empresas generadoras; y clientes regulados -cuya potencia conectada es igual o inferior a $5000 \mathrm{KW}$, como "pymes" y hogares-, cuyos requerimientos energéticos son abastecidos por empresas distribuidoras, las cuales, a su vez, suscriben contratos de suministro con empresas generadoras bajo procesos licitatorios regulados que se adjudican por precios libre ofertados (entre otros factores). A partir de la dictación de la Ley n. ${ }^{\circ} 20805$, clientes cuya potencia conectada sea superior a $500 \mathrm{KW}$ pueden optar a ser calificados como clientes libres ${ }^{6}$.

Conforme a esta estructura, la energía puede ser comercializada en dos mercados que funcionan, a priori, de forma independiente, con participantes y lógicas diversas: el mercado spot y el mercado de contratos. Este último, a su vez, se encuentra conformado por contratos regulados -celebrados entre distribuidoras y generadoras- y por contratos negociados de forma libre -celebrados entre clientes libres y generadoras-.

El mercado spot lo integran las empresas eléctricas, clientes -clientes libres y distribuidoras- y el Coordinador Independiente del Sistema Eléctrico Nacional ("Coordinador") ${ }^{7}$, y consiste en la plataforma en virtud de la cual se regula el funcionamiento económico de la generación eléctrica bajo dos objetivos: lograr el suministro eléctrico permanente demandado $\mathrm{y}$, a su vez, que dicho suministro sea abastecido al menor costo posible.

5 "Esta distinción resulta de suma importancia, pues de acuerdo a nuestra legislación, el sector generación, por las características propias de su estructura de costos ha sido tradicionalmente considerado como un mercado potencialmente competitivo, y por lo tanto, sujeto a una cierta libertad de precios, y por la otra, los segmentos de la transmisión y distribución han sido considerados como monopolios estructurales o naturales, por lo que se ha establecido que tanto sus tarifas como los más mínimos detalles relativos a la calidad y continuidad de los productos y servicios ofrecidos a público, deberán quedar sujetos a una estricta regulación por parte del Estado”, CASTILlo (2017), p. 71.

${ }^{6}$ Art 147 de la LGSE.

${ }^{7}$ Art. 212 de la LGSE: "Coordinador Independiente del Sistema Eléctrico Nacional, el Coordinador. El Coordinador Independiente del Sistema Eléctrico Nacional es el organismo técnico e independiente encargado de la coordinación de la operación del conjunto de instalaciones del sistema eléctrico nacional que operen interconectadas entre sî”. 
El Coordinador debe velar por el equilibrio de ambos objetivos, ordenando el despacho por "orden de mérito" de las centrales: conforme al nivel de la demanda de energía eléctrica que se observe por parte de los clientes, entrarán en funcionamiento las centrales cuyo costo variable de producción sea menor -operadoras más "eficientes"-y, progresivamente, se irán despachando las siguientes centrales más "caras" hasta la última que sea necesaria para abastecer los consumos de energía.

De esta forma, el funcionamiento del mercado eléctrico chileno se estructura bajo un modelo marginalista, pues el costo de operación real del sistema eléctrico se fija según el costo variable de la unidad generadora más cara que tuvo que ser despachada para abastecer la demanda de energía eléctrica ${ }^{8}$. Precisamente, dicho costo se conoce como costo marginal ${ }^{9}$ y será el precio al cual se remunerará la inyección de energía de las centrales que sean despachadas por parte del Coordinador. Así, el funcionamiento del mercado spot busca simular una especie de mercado "perfecto": mediante la intermediación de un tercero -el Coordinadorse busca coincidir la oferta y demanda de energía y potencia eléctrica de corto plazo, al menor costo operacional posible.

El mercado de contratos tiene una lógica distinta y se desarrolla con independencia de las oscilaciones del mercado spot. En aquel mercado, las empresas generadoras suscriben PPA de mediano o largo plazo con empresas distribuidoras o clientes libres, pactándose una serie de cláusulas que regirán los compromisos asumidos en los contratos, principalmente con relación al precio y al volumen de suministro. Mientras los contratos suscritos con empresas distribuidoras se regulan por procesos licitatorios de responsabilidad de la CNE, mediante los cuales se adjudican bloques de suministro acorde a la demanda proyectada y en virtud de los precios ofertados más competitivos ${ }^{10}$, los contratos celebrados con clientes libres son producto de negociaciones libremente sostenidas.

A diferencia del precio spot, los precios acordados en contratos de suministro reflejan factores asociados a situaciones de largo plazo. Las

${ }^{8}$ Asimismo, el sistema se preocupa de remunerar la potencia de punta o cargo por capacidad, cuyo precio se relaciona con el costo marginal de ampliar la capacidad de producción debido a un aumento de la demanda máxima.

Por su parte, el costo marginal es calculado por el Coordinador de forma horaria y por cada barra que compone el sistema eléctrico.

9 "Costo en que se incurre para suministrar una unidad adicional de producto para un nivel dado de producción. Alternativamente, dado un nivel de producción, es el costo que se evita al dejar de producir la última unidad", letra f, art. 225 de la LGSE.

${ }^{10} \mathrm{Si}$ bien el precio ofertado es el principal componente que se toma en cuenta a la hora de adjudicar bloques de suministro, de conformidad a la Ley n. ${ }^{\circ} 20805$ se incorporaron otros factores que deben tomarse en consideración por parte de la CNE. Véase el art. 131 bis de la LGSE. 
generadoras, por su parte, tienen la necesidad de percibir un precio que sea cierto y estable ${ }^{11}$, sobre todo cuando los contratos suscritos respaldan el financiamiento para la construcción de centrales eléctricas. Los clientes libres -así como los regulados-, por su lado, también ven como un beneficio relevante el obtener un precio estable para el desarrollo de sus actividades económicas y domésticas. Sea uno u el otro caso, en contratos de suministro eléctrico que se pactan por largos periodos resulta fundamental proyectar cuál será el costo de desarrollo de la matriz eléctrica, es decir, cuál será la tecnología empleada para viabilizar proyectos en el futuro, pues dicha proyección, como explicaremos a continuación, involucra riesgos tanto para las generadoras como para los consumidores.

Si bien el mercado spot funciona con independencia del mercado de los contratos, ambos se encuentran estrechamente relacionados. Una vez que, conforme a la demanda de energía y a los costos variables de las centrales disponibles, se ha inyectado al sistema la cantidad de energía que fuera necesaria abastecer, las generadoras que tengan compromisos de suministro deben comprar del sistema la energía al costo marginal horario -lo que se conoce como "retiro" - hasta por las cantidades acordadas en dichos compromisos, para luego vender la energía retirada según los términos acordados en sus contratos (al precio contractual convenido). Sin embargo, como el despacho de las centrales se efectúa por orden de mérito y sin tomar en consideración los contratos suscritos entre consumidores y generadoras, existirán centrales que serán excedentarias y otras que serán deficitarias, es decir, algunas que producirán más y otras menos en comparación a los requerimientos energéticos de sus clientes, dando lugar a transferencias económicas entre ellas: las centrales que retiraron energía por sobre su producción deberán remunerar a las que lo hicieron por debajo.

De esta forma, y como veremos más adelante, el desenvolvimiento del mercado spot puede generar dos tipos de efectos en los contratos de suministro: primero, a nivel de volumen de suministro, por cuanto el perfil de producción de las centrales puede ser menor a los requerimientos energéticos de sus clientes y, segundo, en el ámbito de precios, pues los niveles de costos marginales diferirán de los precios acordados en los contratos.

${ }^{11}$ En este sentido, resulta ilustrativo el caso de la central Campanario, generadora que adoptó la estrategia de abastecer contratos de suministro desde el mercado spot. Sin embargo, hacia el año 2011 los costos marginales estaban en altos niveles, muy por encima de los precios pactados en sus contratos de suministro, lo que causó la quiebra de la central. 


\section{EVOLUCIÓN DEL MERCADO ELÉCTRICO NACIONAL}

Nuestro mercado spot se ha caracterizado por presentar variaciones relevantes tanto durante el transcurso de los años, al interior de un mismo año o, incluso, mes a mes. Sin embargo, a continuación analizaremos dos marcos temporales que se diferencian en una doble perspectiva, primero, con relación a las estructuras que presentó el mercado eléctrico durante dichos periodos y, segundo, a las causas que explican esas estructuras.

\section{A. Mercado eléctrico chileno al 2014: costo de desarrollo en base a energías convencionales}

Desde la dictación de la LGSE en la década de 1980 hasta 2014, el costo de desarrollo de la matriz estuvo gobernado por energías convencionales, distinguiéndose dos etapas a partir de la crisis del gas argentino, cuyo punto cúlmine ocurrió el año 2006. Hasta antes de dicho año, el gas natural era uno de los insumos predominantes para el abastecimiento del sistema eléctrico chileno, llegando, el año 2005, a proveer el 29\% de la generación eléctrica bruta, mientras que las hidráulicas de embalse, pasada y las centrales a carbón abastecían un $32 \%, 18 \%$ y $18 \%$, respectivamente ${ }^{12}$. Casi no existían centrales renovables relevantes en funcionamiento debido a sus altos costos de generación.

Luego del corte del suministro de gas desde Argentina, el mercado tuvo un notable giro hacia el carbón: a 2014, la generación eléctrica de centrales sobre la base de dicho combustible aumentó a un $41 \%{ }^{13}$ del total nacional de generación -más del doble existente el año 2005-, mientras que las generadoras a gas disminuyeron a un 15\% -casi la mitad con relación con el periodo anterior-. Las hidráulicas de embalse y pasada disminuyeron también a un 18\% y $15 \%$ respectivamente, y las centrales renovables comenzaron a aparecer de a poco. Por ejemplo, el año 2014 un $2 \%$ de la generación bruta fue suministrada por plantas eólicas ${ }^{14}$.

${ }^{12}$ CNE (2018), p. 28.

${ }^{13}$ El SING, por su mayor dependencia del gas natural, experimentó cómo el carbón lo reemplazó hasta llegar al 82\% de ocupación en su matriz hacia el 2013. Véase "Análisis histórico de los precios de energía eléctrica en minería y su impacto en competitividad", p. 4. Disponible en www.cochilco.cl/Listado\%20Temtico/Analisis $\% 20$ Historico $\% 20$ de $\% 20$ Precios $\% 20$ de $\% 20$ EE $\% 2024-12-2014 \% 20$ vf.pdf [fecha de consulta: 20 de agosto de 2019].

${ }^{14}$ CNE (2018), p. 28. 


\section{B. Año 2015 hacia el futuro: \\ costo de desarrollo sobre la base de ERNC}

A pesar de que hasta 2014 el desarrollo de la matriz eléctrica chilena había estado marcado por centrales convencionales, desde hace varios años nuestro país venía trabajando en aumentar y facilitar el desarrollo de nuevos proyectos energéticos que fueran amigables con el ambiente. De hecho, la situación energética actual y los cambios de paradigma que ha sufrido el sistema eléctrico nacional en el último tiempo, son el resultado de un largo camino y la dictación de varias leyes, junto con un drástico descenso en los costos de la tecnología de generación eléctrica ERNC.

Como analizaremos, sin la adecuación de nuestro sistema legal no se habría podido aprovechar este avance tecnológico de la industria de la generación, en virtud del cual los costos de construcción y operación de centrales ERNC se redujeron de manera significativa, viabilizando la entrada de estos proyectos a nuestra matriz y disminuyendo los precios de la energía eléctrica.

\section{i. Cambios regulatorios del sistema eléctrico chileno}

16 Desde su promulgación, la LGSE ha experimentado más de treinta modificaciones regulatorias con distintos alcances y propósitos relacionados con las tres grandes áreas del mercado eléctrico: generación, transmisión y distribución.

El camino legislativo para incentivar la participación de ERNC se construyó, en los últimos quince años, principalmente a partir de dos pilares: primero, el perfeccionamiento del sistema de licitaciones de suministro para clientes regulados, de modo de incentivar una desconcentración y mayor competitividad del mercado eléctrico y, segundo, el establecimiento de porcentajes mínimos de retiro o comercialización de energía que debían ser suministrados por fuentes renovables ${ }^{15}$.

${ }^{15}$ Sin embargo, a nivel de transmisión también encontramos incentivos a las ERNC. De hecho, la primera señal de apoyo a estas centrales fue la Ley n. ${ }^{\circ} 19940$ (Ley "Corta I"), promulgada el 12 de marzo de 2004, que introdujo por primera vez el concepto de generación no convencional: "La ley establece la exención para estas centrales del pago total o parcial de los peajes asociados al sistema troncal por transportar la energía del lugar donde es generada al lugar donde es consumida, en la medida en que su capacidad de generación inyectada al sistema sea menor a $20 \mathrm{MW}$. Sin embargo, si la cantidad de generadores exceptuados de peaje excede el 5 por ciento de la capacidad instalada del sistema, éstos deberán incurrir en un pago proporcional por la parte que excede el 5 por ciento. Así, esta ley otorgó el primer incentivo a las centrales renovables no convencionales y a la cogeneración eficiente”. ClerC et al. (2017), p. 30. 


\section{a. Licitaciones de suministro eléctrico} para clientes regulados

El año 2005 se promulgó la Ley n. ${ }^{\circ} 20018$ ("Ley Corta II") ${ }^{16}$ con el objetivo de robustecer la seguridad del suministro frente a incertidumbres externas $^{17}$ en el abastecimiento de combustibles de difícil sustitución inmediata y aumentar la competencia en el mercado de la generación eléctrica facilitando el ingreso de nuevos actores ${ }^{18}$. Para ello, la Ley Corta II innovó con un mecanismo de licitaciones de contratos de suministro ${ }^{19}$ sustituyendo el inciso segundo del art. 79 de la LGSE, por

"un proceso de licitación que define contratos con plazos extendidos, durante cuya vigencia el precio de adjudicación no es modificado, sin perjuicio de las indexaciones que deban llevarse a cabo en virtud de cambios en variables asociadas a los costos de proveer el servicio" 20 .

Así, esta ley pretendía introducir mejoras relevantes en el mercado eléctrico a través de procesos de licitación transparentes y regulados que dieran certeza a la inversión ${ }^{21}$.

Un segundo apoyo a las ERNC, también a nivel de transmisión, fue la Ley n. 20936, promulgada el 26 de septiembre de 2014 y que, además de viabilizar proyectos verdes al imputar la totalidad de los costos de transmisión a los clientes finales, trató el concepto de Polos de Desarrollo de Generación: “...esta ley crea el concepto de Sistemas de Transmisión para Polos de Desarrollo de Generación, los que estarán destinados a evacuar la producción de la generación de dichas zonas con potencial de generación de ERNC. El Ministerio de Energía debe determinar la existencia de zonas con potencial relevante de generación de ERNC, cuyo aprovechamiento resulte de interés público". CLERC et al. (2017), p. 34 y ss.

De forma indirecta, la fijación de un impuesto al carbono establecido por la Ley n. ${ }^{\circ} 20780$ también ha contribuido al crecimiento de las ERNC en el país, al incrementar el costo de desarrollo de generadoras convencionales como termoeléctricas o de ciclo combinado que usen gas o petróleo diésel (sin perjuicio de que estos mayores costos son usualmente traspasados al cliente, sea libre o regulado).

${ }^{16}$ La Ley n. ${ }^{\circ} 19940$ modificó principalmente la regulación de la transmisión eléctrica.

${ }^{17}$ Con la Ley Corta II se buscaba "despejar la incertidumbre en el mercado eléctrico para el desarrollo de futuras inversiones en generación, restaurando y reforzando, de este modo, la seguridad tradicional de abastecimiento eléctrico para el país", Evans y YáñEZ (2017), p. 193.

${ }^{18}$ Historia de la ley, n. ${ }^{\circ} 2018$. Disponible en www.bcn.cl/historiadelaley/nc/historiade-la-ley/5572/ [fecha de consulta: 2 de junio de 2019].

${ }^{19}$ En un principio, los contratos de suministro eran libremente negociados entre las generadoras y empresas distribuidoras, salvo los precios que eran fijados por la CNE para cada semestre según el precio del nudo correspondiente.

${ }^{20}$ Evans y YÁÑEz (2017), p. 193.

${ }^{21}$ Las principales características de las licitaciones de suministro eran las siguientes: (i) el proceso estaría controlado por las distribuidoras, las que debían convocar las licitaciones con 
Sin perjuicio de esta reforma, los resultados de las licitaciones bajo la vigencia de la Ley Corta II no fueron los esperados: de las diecisiete licitaciones -desde la 2006/1 hasta la 2013/1- que se convocaron al amparo de esta le $^{22}$, siete fueron declaradas totalmente desiertas. En las diez restantes, grandes porcentajes de bloques de energía no fueron adjudicados y otros tantos lo fueron a precios altos debido a una inflexibilidad de los procesos: al ser público el precio máximo de oferta económica que establecía la CNE, no se presentaban ofertas cuando los costos de desarrollo del sistema estaban por sobre dicho máximo; y en las licitaciones en que las generadores sí ofertaron, los precios por lo general bordeaban los máximos publicitados. Por otro lado, tampoco se logró la entrada de nuevas generadoras al mercado eléctrico, pues casi la totalidad de la oferta, hasta el año 2014, se concentraba en las empresas Colbún, Endesa y AES Gener ${ }^{23}$, las que tampoco ofrecían nuevos proyectos que ampliaran la matriz eléctrica y disminuyeran los precios de energía.

Estos dos factores repercutían en los niveles de precios del mercado spot-que, hacia los años 2012 y 2013, superaban los $250 \mathrm{USD} / \mathrm{MWh}^{24}-\mathrm{y}$, consecuentemente, afectaban los resultados de las licitaciones de suministro: mientras que en la licitación 2012/03, segundo llamado, los precios llegaron a 139,90 USD/MWh, en la licitación 2013/01 ascendieron a 128,93 USD/ MWh. Este alto nivel de precios impactaba tanto el consumo de los hogares -clientes regulados- como el de los clientes libres - principalmente, empresas mineras, que se veían impedidas de acceder a contratos más baratos por escasez de oferta-, las que perdían competitividad en comparación al nivel de precios de la electricidad en el resto de América Latina y el mundo ${ }^{25}$.

Frente a este complejo escenario eran urgentes contar con reformas legislativas que destrabaran el mercado eléctrico, pero como se sabía que dichas reformas tomarían tiempo, se comenzaron a introducir nuevas prácticas en el ámbito reglamentario. Una de las más relevantes ${ }^{26}$ fue la rea-

una anticipación mínima de tres años a la fecha de inicio del suministro; (ii) adjudicación de bloques de suministro según el libre juego de la oferta y la demanda, de modo de obtener los precios más bajos posibles para los clientes regulados; (iii) plazos de contratos de suministro de hasta 15 años y (iv) se establecía la existencia de un precio público máximo para las ofertas, el cual sería fijado semestralmente por la CNE. Véase CNE (2017), p. 31 y ss.

${ }^{22}$ Compartimos la opinión vertida en CNE (2017) con relación a que las dos licitaciones previas a la Ley n. 20805 obedecen a un periodo de transición, pues se implementaron prácticas que luego se recogieron normativamente en dicha ley.

${ }^{23}$ Véase tabla 5, CNE (2017).

${ }^{24}$ Systep (2012), p. 6.

${ }^{25}$ Argüello (2012).

${ }^{26}$ Antes, en la licitación 2013/03, primer llamado, se incorporó un cambio relevante: el precio máximo que podía ser ofertado por las generadoras dejó de ser público -como lo era bajo la vigencia de la Ley Corta II- al regularse el "precio de reserva" en la sección 
lizada en la licitación 2013/03, segundo llamado, que permitió la licitación por bloques horarios. Con ello, se viabilizaba la participación de centrales ERNC en estos procesos ${ }^{27}$, pues como estas dependen de "combustibles" o insumos primarios que varían significativamente según la hora del día (como la energía solar o eólica), podrían ofertar por los bloques horarios en que dichas centrales funcionan a plenitud (i.e. bloques diurnos para las plantas fotovoltaicas $)^{28}$. Como consecuencia, los resultados de la licitación fueron más que positivos: por un lado, se aumentó la competitividad mediante la incorporación de nuevos incumbentes que rompían el tradicional esquema de las generadoras convencionales, llegándose a adjudicar cerca del $90 \%$ de los bloques disponibles y, por otro, los precios adjudicados cayeron, en promedio, cerca de un $20 \%$ con relación al último proceso, acercándose a la barrera de los USD $100 \mathrm{MWh}^{29}$.

8.2 de las Bases de Licitación, modificada por la resolución exenta n. ${ }^{\circ} 232$ de la CNE, lo que trajo como resultado una rebaja en los precios adjudicados de casi $20 \mathrm{USD} / \mathrm{MWh}$. Endesa se adjudicó quince subbloques por un total de 681,810 GWh-año, a 112 USD/ MWh. Disponible en https://sic.coordinador.cl/wp-content/uploads/2014/07/2014-0814-Acta-Adjudicaci\%C3\%B3n-Primera-Etapa.pdf [fecha de consulta: 17 de junio de 2019].

27 "Dentro del diseño de las bases para dirigir o guiar las licitaciones hacia el cumplimiento de objetivos como mayor competencia y diversificación, desde la Licitación 2013/03-Segundo Llamado se han introducido los denominados 'Bloques Horarios' a lo largo del día, con el objetivo de adaptarse a tecnologías que solo pueden generar en determinadas horas, como es el caso de las energías obtenidas a través de la radiación solar y energía eólica. Como señala González y Palma: 'La partición de ofertas en bloques horarios debiera facilitar el ingreso de generadores no convencionales, a su vez de fomentar la competencia entre ellas. Previo a esta medida, las ERNC debían ofertar un bloque completo (24 horas), lo que las obligaba a comprar energía spot en los horarios que no podían generar o procurarse de contratos de largo plazo con generadores convencionales'", CNE (2017), p. 65; "Sin perjuicio de ello, pareciera que el papel jugado por la CNE en los últimos procesos de licitación y en el diseño de las bases administrativas, han sido determinantes para el ingreso de generadores de ERNC. Lo afirmado, tras bajar las barreras de entrada existentes en el anterior marco normativo, y en particular en lo que respecta a la definición de diferentes bloques horarios a licitar permitiendo la competencia de tecnologías variables -otrora excluidas- trajo como consecuencia una inmediata disminución en los precios de adjudicación de contratos", GATICA (2017), p. 89.

${ }^{28}$ La sección 3.2 de las Bases de Licitación 2013/03, segundo llamado, bajo el título "Ofertas económicas para bloques de suministro", contempló la licitación de tres bloques de suministro horario: (i) entre las 00:00 hrs. y las 07:59 hrs. y entre las 23:00 hrs. y las 23:59 hrs.; (ii) entre las 08:00 hrs. y las 17:59 hrs. y (iii) entre las 18:00 hrs. y las 22:59 hrs.

${ }^{29}$ Resultados de la licitación disponibles en: https://sic.coordinador.cl/informacionadicional/licitaciones/items/licitacion-2013-03/ [fecha de consulta: 7 de agosto de 2019]; "El 1 de diciembre de 2014, diecisiete empresas presentaron ofertas en el proceso. Se adjudicaron bloques de demanda equivalente a un consumo de $11.955 \mathrm{GWh}$ /año a un precio medio (ponderado por la energía de los bloques) de US\$ 108,150 por MWh. El precio mínimo ofertado y adjudicado fue US\$ 79,880 por MWh, correspondientes a 120 $\mathrm{MWh}$ /año en el bloque 2-B. Esta oferta estuvo asociada a la empresa Santiago Solar S.A., 
Ante las evidentes mejoras introducidas en el mercado eléctrico a través de la regulación de las licitaciones de suministro, el camino a seguir era claro: se necesitaba una reforma legislativa que, haciendo suyas las prácticas que la CNE había estado implementando, continuara perfeccionando los procesos licitatorios y corrigiendo algunos de los inconvenientes y efectos no deseados que dejó la operación práctica de la Ley Corta $\mathrm{II}^{30}$. Fue así como se dictó la Ley n. ${ }^{\circ} 20805$, promulgada en enero de 2015 y que "perfecciona el sistema de licitaciones de suministro eléctrico para clientes sujetos a regulaciones de precios". Como se aprecia en su mensaje presidencial ${ }^{31}$, esta ley tuvo como propósito central diversificar la oferta eléctrica y, como consecuencia, lograr una disminución de los precios de la energía ${ }^{32}$.

con un proyecto de energía renovable solar", reporte "Utilización de bloques horarios en licitación de suministro a distribuidoras: caso licitación sic 2013/03 - $2^{\circ}$ llamado", preparado por Inodú. Disponible en www.acera.cl/wp-content/uploads/2015/02/Minuta-Acera20122014b.pdf [fecha de consulta: 12 de agosto de 2019]; Artículo de prensa "Con éxito sin precedentes termina proceso de licitaciones de suministro SIC". Disponible en www. electricas.cl/con-exito-sin-precedentes-termina-proceso-de-licitaciones-de-suministro-sic/ [fecha de consulta: 12 de agosto de 2019].

30 "El supuesto del legislador de que en tres años máximos se podía restablecer el equilibrio entre oferta y demanda, superando el rezago de inversiones que estaba deter20 minado por una fuerte alza del costo marginal, no fue tal. La falta de competencia en el proceso de licitaciones, con precios cada vez mayores, ausencia de nuevos participantes, energía de base contratada concentrada en las tres principales generadoras del país, y costos marginales esperados del sistema por sobre los precios máximos fijados, en las licitaciones, evidenció un nuevo descalce entre una demanda creciente y una estrechez de la oferta por parte de las empresas generadoras”, Evans y YáñEZ (2017), p. 197.

31 "Diversos estudios apuntan que uno de los problemas del mercado eléctrico estaría asociado a la falta de competencia en el mercado de generación. En efecto, en un reciente estudio encargado por la Fiscalía Nacional Económica, se indica que 'la forma de las ofertas en las licitaciones de distribución no son consistentes con competencia perfecta (entendiendo por esta última ofertas cercanas al coste de oportunidad de proveer energía). De la misma forma podemos descartar conductas del tipo colusivas (i.e. acciones concertadas para levantar precios). Encontramos en cambio una competencia imperfecta con un ejercicio de poder de mercado de tipo unilateral o no-cooperativo'. Dicho informe advierte que el alza de los precios ya está restando competitividad a la industria chilena y comienza a transmitirse paulatinamente a las familias. En el SIC, las tres empresas más grandes de generación eléctrica y sus relacionadas, poseen más de un 76\% de la capacidad instalada, mientras que en el SING alcanza el 98\%”, Mensaje presidencial de la Ley $n .^{\circ} 20.805$. Disponible en www.bcn.cl/historiadelaley/fileadmin/file_ley/3951/HLD_3951_749a0d2 dec7072ac83d52ebf0f2ff393.pdf [fecha de consulta: 13 de agosto de 2019].

32 "Teniendo claridad acerca del diagnóstico, hubo también consenso en que el instrumento clave para mejorar el estado del mercado eléctrico eran las licitaciones de suministro para clientes regulados, dado que estos representan cerca del 50\% de la demanda de consumo eléctrico del SIC y el SING. En consecuencia, el marco regulatorio de los procesos de licitación resultaba crucial para la consecución de los siguientes cuatro objetivos relacionados entre sí: a) Disminuir los precios de la energía eléctrica; b) Aumentar 
Dentro de las grandes reformas introducidas por la Ley n. ${ }^{\circ} 20805$ a la LGSE, encontramos que, con el fin de transparentar y hacer más competitivos los procesos, la responsabilidad de las licitaciones de suministro pasó a recaer exclusivamente en la $\mathrm{CNE}^{33}$ (antes las empresas distribuidoras tenían responsabilidad en el diseño de las bases, coordinación y dirección de los procesos ${ }^{34}$ ). Así, se lograba evitar cualquier conflicto de interés que pudiera "contaminar" el proceso licitatorio mediante el cual las distribuidoras cumplían su obligación legal ${ }^{35}$ de contar con contratos de suministros para abastecer la demanda de los clientes regulados ${ }^{36}$. Otras modificaciones relevantes fueron:

i) la ampliación de ciertos plazos para promover la construcción de nuevas centrales ${ }^{37}$,

la competencia en el sector eléctrico; c) Incorporar nuevos actores en el segmento de generación, disminuyendo las barreras de entrada, y d) Diversificar las fuentes de energía", CNE (2017), p. 50.

33 "La Comisión deberá diseñar, coordinar y dirigir la realización de tales procesos de licitación, cuyo objeto será que las concesionarias de distribución dispongan de contratos de suministro de largo plazo para satisfacer los consumos de sus clientes sometidos a regulación de precios, con una antelación mínima de cinco años a la fecha de inicio del suministro", art. 131, inc. 2 de la LGSE.

${ }^{34}$ La Ley Corta II entregó el proceso de licitación a las distribuidoras, pero debiendo ser aprobada sus bases y modificaciones por la CNE: "Las bases para licitaciones, individuales o conjuntas, serán elaboradas por las concesionarias y deberán ser aprobadas previamente por la Comisión”, ex art. 79-2 de la LGSE.

35 "Las concesionarias de servicio público de distribución deberán disponer permanentemente del suministro de energía que les permita satisfacer el total del consumo de sus clientes sometidos a regulación de precios. Para dichos efectos, aquéllas deberán contar con contratos de suministro, los cuales deberán ser el resultado de procesos de licitación pública. Dichos procesos no podrán incluir consumos de clientes no sometidos a regulación de precios, como tampoco se podrán incluir posteriormente en la ejecución de los contratos resultantes", art. 131, inc. 1 de la LGSE.

36 “[...] si bien era efectivo que las distribuidoras tenían la obligación de contar con contratos que aseguraran el suministro por la obligación legal que pesa sobre ellas en tanto concesionarias de un servicio público, no existían reales incentivos para contratar tal suministro de manera eficiente, ya que si se considera que cualquiera sea el precio ofertado por los proponentes en una licitación, estos serán en definitiva traspasados y soportados por los clientes regulados (pass through), entonces las distribuidoras, en tanto aseguren el suministro para satisfacer su demanda, debiera serles relativamente indiferente o de menor impacto, en términos económicos, lo que las generadoras les cobren por la energía. Más aún, las empresas distribuidoras tenían incentivos a contar con suministro contratado y carecían de desincentivos para tener más contratación de la necesaria, por lo que se generaban condiciones para una sobrecontratación, lo que conlleva riesgos para las compañías generadoras que encarecen sus precios al quedar expuestas a un menor ingreso por sus contratos", CNE (2017), pp. 51-52.

${ }^{37}$ Se amplió el plazo de anticipación de las licitaciones a cinco años con relación a la época en que se iniciarían los suministros licitados (art. 131, inc. 2 de la LGSE) y se 
ii) el precio máximo de las ofertas de energía dejó de ser público ${ }^{38}$ y se determinará, en cambio, mediante un acto administrativo de carácter reservado por parte de la $\mathrm{CNE}$, el que solo se publicitaría en las aperturas de las ofertas ${ }^{39} \mathrm{y}$

iii) se contempló la posibilidad de que en las bases de licitación se considerara no solo el factor precio a la hora de adjudicar los bloques de suministro, sino que, también, otros factores de evaluación ${ }^{40}$, además de fórmulas de indexación de las ofertas acorde a ciertas variables que pudieran afectar el costo del suministro ${ }^{41}$.

prolongó la duración máxima de los bloques de suministro de quince a veinte años (art. 132, inc. 2 de la LGSE).

${ }^{38}$ Ex art. $101^{\circ}$ ter. de la LGSE.

39 "En cada licitación el valor máximo de las ofertas de energía, para cada bloque de suministro, será fijado por la Comisión, en un acto administrativo separado de carácter reservado, que permanecerá oculto hasta la apertura de las ofertas respectivas, momento en el cual el acto administrativo perderá el carácter de reservado. Con todo, dicho valor máximo deberá ser fundado y definirse en virtud del bloque de suministro de energía licitado, del período de suministro y en consideración a estimaciones de costos eficientes de abastecimiento para cada caso. El reglamento establecerá los procedimientos administrativos que correspondan para asegurar la confidencialidad del valor máximo de las ofertas", art. 135, de la LGSE.

40 “Corresponderá a la Comisión, anualmente, y en concordancia con los objetivos de eficiencia económica, competencia, seguridad y diversificación que establece la ley para el sistema eléctrico, determinar las licitaciones de suministro necesarias para abastecer, al menor costo de suministro, los consumos de los clientes sometidos a regulación de precios, sobre la base de la información proporcionada por las concesionarias de servicio público de distribución señalada en el artículo anterior. Para los efectos de lo dispuesto en este inciso, se entenderá por diversificación la obligación que establece el inciso primero del artículo 150 bis", art. $131^{\circ}$ bis de la LGSE.

41 "Las empresas concesionarias de distribución deberán adjudicar la licitación a aquellas ofertas más económicas, de acuerdo a las condiciones establecidas en las bases de licitación para su evaluación, debiendo comunicar a la Comisión la evaluación y la adjudicación de las ofertas, para los efectos de su formalización, a través del correspondiente acto administrativo. Los criterios de evaluación económica establecidos en las bases de licitación podrán considerar las fórmulas de indexación de las ofertas a lo largo del período de suministro, así como también criterios que favorezcan la evaluación de aquellas ofertas que aseguren el cumplimiento de los objetivos a que se refiere el artículo $131^{\circ}$ bis", art. 134, inc. 1 de la LGSE.

En GonzÁlez y PAlma (2017) se afirmaba lo siguiente: “Con el sistema anterior, todo el riesgo del cambio en los valores del indexador -como precio del petróleo- era traspasado al cliente residencial. El precio nivelado tiene incorporado el largo plazo en la evaluación, pues contiene información respecto a los valores futuros esperados de los indexadores de costos propios de la generación de energía. Para ello se emplea la proyección de los índices de combustibles publicada en el Annual Energy Outlook publicado por el EIA de Estados Unidos. Se espera que con este cambio, los oferentes internalicen el largo plazo en sus ofertas a través del conjunto de indexadores propuestos, de manera que las ofertas se comparen sobre una base común respecto del valor presente esperado del contrato", p. 15. 


\section{b. Promoción de centrales ERNC}

Otra técnica legislativa empleada en el país para promover las ERNC, consiste en fijar un porcentaje mínimo de suministro que deba ser abastecido por ellas. Si bien un primer paso lo encontramos en la Ley Corta $\mathrm{II}^{42}$, la disposición tuvo poca vigencia al ser reemplazada por la Ley n. ${ }^{\circ} 20257$, publicada el año 2008 y que modificó la LGSE incorporando un nuevo art. 150 bis:

"cada empresa eléctrica que efectué retiros de energía desde los sistemas eléctricos con capacidad instalada superior a 200 megawatts para comercializarla con distribuidoras o con clientes finales, estén o no sujetos a regulación de precios, deberá acreditar ante la Dirección de Peajes del CDEC respectivo, que una cantidad de energía equivalente al 10\% de sus retiros en cada año calendario haya sido inyectada a cualquiera de dichos sistemas, por medios de generación renovables no convencionales, propios o contratados" $\$ 3$

Esta reforma -que tenía una obligatoriedad escalonada hasta el año $2024^{44}$ - convirtió a Chile en uno de los primeros países en fijar porcentajes mínimos de retiros asociados a ERNC.

42 "Sin perjuicio del derecho a ofertar en las licitaciones reguladas en los artículos $79^{\circ}-1$ y siguientes, en las condiciones que establezcan las respectivas bases, los propietarios de medios de generación a que se refiere el artículo $71^{\circ}-7$ tendrán derecho a suministrar a los concesionarios de distribución, al precio promedio señalado en el inciso primero de este artículo, hasta el 5\% del total de demanda destinada a clientes regulados. Los procedimientos para dar cumplimiento a lo establecido en este artículo se contendrán en el reglamento", ex art. 96 ter. de la LGSE, introducido por la Ley Corta II; "Los propietarios de los medios de generación conectados al sistema eléctrico respectivo cuya fuente sea no convencional, tales como geotérmica, eólica, solar, biomasa, mareomotriz, pequeñas centrales hidroeléctricas, cogeneración y otras similares determinadas fundadamente por la Comisión, cuyos excedentes de potencia suministrada al sistema sea inferior a 20.000 kilowatts, estarán exceptuados del pago total o de una porción de los peajes por el uso que las inyecciones de esos medios de generación hacen de los sistemas de transmisión troncal, conforme a los criterios establecidos en los incisos siguientes", ex art. 71-7 de la LGSE.

${ }^{43}$ Esta obligación se aplicaba a todas las generadoras que suscribiesen contratos con distribuidoras o con clientes libres con posterioridad a agosto de 2007, contemplándose una multa en caso de infracción de 0,4 UTM/MWh para los primeros tres años, y de 0,6 $\mathrm{UTM} / \mathrm{MWh}$, a partir del cuarto.

44 “Con todo, la obligación aludida en el inciso primero será de un 5\% para los años 2010 a 2014, aumentándose en un 0,5\% anual a partir del año 2015. Este aumento progresivo se aplicará de tal manera que los retiros afectos a la obligación el año 2015 deberán cumplir con un 5,5\%, los del año 2016 con un 6\% y así sucesivamente, hasta alcanzar el año 2024 el $10 \%$ previsto en el artículo $150^{\circ}$ bis", art. 1 transitorio de la Ley n. 20257. 
Cinco años más tarde, fue materia de arduo debate $-y$ resistencia por parte de ciertas asociaciones gremiales- la posibilidad de incrementar la meta del 10\% de retiros a un 20\%, y adelantar la obtención de dicha meta para el año 2020 (el proyecto "20/20"). Las principales objeciones a esta propuesta eran dos: la potencial inestabilidad que podría ocasionar un aumento de la participación de ERNC en el sistema eléctrico nacional -pues se trata de centrales que, por lo general, poseen un bajo factor de planta que no permiten asegurar un suministro estable de energía-y el eventual aumento de costos que para los usuarios se desencadenaría ${ }^{45}$.

Finalmente, mediante la Ley n. ${ }^{\circ} 20698$, de octubre de 2013, se lograba profundizar aún más la penetración de ERNC en el mercado nacional

${ }^{45}$ Artículo de prensa "Forzar la incorporación de ERNC genera una distorsión y un mayor costo para el país". Disponible en www.economiaynegocios.cl/noticias/noticias. asp?id=100757 [fecha de consulta: 19 de junio de 2019].

El informe titulado "Matriz energética: la ceguera del proyecto de ley 20/20" (2012), preparado por Libertad y Desarrollo", de fecha 27 de enero de 2012, concluía lo siguiente: "el proyecto 20/20 es ejemplo de una mala política pública, pues podría obligar a incorporar masivamente proyectos de ERNC aún cuando éstos sean ineficientes. Lo anterior abre una serie de interrogantes en cuanto a los sobrecostos comprometido 24 en esta meta, tanto en generación como transmisión; el eventual desplazamiento de proyectos convencionales y el riesgo asociado para la capacidad de generación de base; y el sobrecosto que se estaría pagando para compensar las emisiones de CO2”. Disponible en https://lyd.org/wp-content/uploads/2012/02/TP-1050-Matriz-EnergeticaLa-Ceguera-del-Proyecto-de-Ley-2020-27-01-2012.pdf [fecha de consulta: 19 de junio de 2019].

En RAINERI (2018) se retrataba la situación descrita: "La diversidad de posiciones que generaba el grado de desarrollo de las ERNC y la meta de 20\% al 2020, se vio reflejada en una variedad de análisis que abordaron el tema. Analista de LyD en IRE Summit 2010 afirma que 'resultaría conveniente retrasar el compromiso de elevar a 20\% la participación de las ERNC en la matriz energética en 2020'. Una nota de analistas publicada por el mismo centro de estudios, concluye que: 'Cualquier esfuerzo por aumentar la penetración de las ERNC en la matriz conllevará un aumento de los costos totales de suministro del sistema eléctrico y por consiguiente de los precios a consumidores finales', o los mismos analistas en Costos de integración de ERNC intermitentes y estacionales: convergiendo costos privados con costos sociales. En un estudio para la Cámara Chilena de la Construcción, El costo diferencial de las alternativas de generación en el SIC, sobre el impacto del 20/20, los académicos de la Universidad de los Andes, A. Galetovic y C. Hernández, indican que la implementación de la nueva ley provocaría un impacto en el sistema eléctrico similar al que provocó la falta de gas argentino como insumo para generar energía. Galetovic es partidario de eliminar cualquier meta, incluso el requisito estipulado en la ley que opera desde 2007, que considera llegar a 10\% a 2024. En una posición intermedia la Comisión Asesora de Desarrollo Energético (CADE), en noviembre de 2011 entrego su Informe con propuestas de desarrollo del sector donde propuso elevar la meta establecida en la Ley $\mathrm{N}^{\circ} 20.257$, sobre penetración de las ERNC en la matriz eléctrica, de 10\% para el año 2024 a 15\% en el mismo año", p. 53. 
a través de la modificación del mencionado art. 150 bis, aumentando el porcentaje mínimo al $20 \% 0^{46}$, pero de manera escalonada hasta el año $2025^{47}$. Además, con esta ley se volvía a resguardar normativamente la participación de fuentes renovables en las licitaciones de suministro, incorporando un nuevo art. 150 ter $^{48}$.

\section{ii. Política nacional de energía}

Complementariamente a los cambios regulatorios recién señalados, Chile ha contado con políticas de energía que han buscado materializar las metas de dichos cambios. Mediante la dictación del decreto supremo n. ${ }^{\circ}$ $148^{49}$, de fecha 30 de diciembre de 2015, la presidenta Michelle Bachelet aprobaba la política energética nacional de largo plazo -impulsada por el ministro de Energía de la época, Máximo Pacheco-, el cual constaba en el documento titulado Energía 2050. Política energética de Chile ("Política energética”). El Decreto tuvo dos objetivos: uno de corto plazo, al año 2025 ,

"donde se sometiera a discusión las líneas de acción, en términos de los estándares, políticas y regulaciones que garanticen la factibilidad técnica y sustentabilidad de la matriz energética";

y otro de mediano y largo plazo, al año 2050, "donde se discutieran aquellos aspectos estratégicos y tecnológicos que definen la matriz energética".

A partir de uno de los pilares en que descansaba la Política Energética, "Energía Compatible con el Medio Ambiente" 51 , el gobierno proponía una

${ }^{46}$ Esta nueva obligación se aplica solo para los contratos de suministro suscritos con posterioridad al 1 de julio del año 2013.

${ }^{47}$ Art. 2, de la Ley n. ${ }^{\circ} 20698$.

48 "Para dar cumplimiento a parte de la obligación establecida en el inciso primero del artículo anterior, el Ministerio de Energía deberá efectuar licitaciones públicas anuales, para la provisión de bloques anuales de energía provenientes de medios de generación de energía renovable no convencional [...]".

${ }^{49}$ Previamente a la dictación de este decreto, la CNE había dictado en el año 2008 la "Política energética: nuevos lineamientos. Transformando la crisis energética en una oportunidad". Como su título lo indica, esta política venía precedida de la crisis del gas argentino, altos precios de los combustibles y una baja participación de ERNC, por lo que las proyecciones futuras y el tipo de políticas que se proponían tenían un alcance diverso. Disponible en www.cne.cl/archivos_bajar/Politica_Energetica_Nuevos_Lineamientos_08. pdf [fecha de consulta: 23 de junio de 2019].

${ }^{50}$ Disponible en www.energia.gob.cl/sites/default/files/energia_2050_-_politica_ energetica_de_chile.pdf [fecha de consulta: 6 de julio de 2019].

${ }^{51}$ Los otros tres pilares obedecían a la Seguridad y calidad de suministro, la Energía como motor de desarrollo y la Eficiencia y educación energética, política energética, p. 11. 
meta doblemente desafiante: por un lado, lograr una entrada masiva de ERNC al mercado eléctrico, llegando al año 2035 con una participación de un 60\% de ERNC, y al año 2050 con, al menos, un 70\%52 y, por otro lado, promover una generación acorde a las políticas internacionales medioambientales, especialmente en relación con la reducción de la emisión de gases de efecto invernadero en un 30\% al año 2030 -en comparación con el año 2007- y lograr al año 2050 un nivel de gases por debajo de los límites indicados por la ciencia ${ }^{53}$, luego de haberse constatado que durante el año 2010 un porcentaje significativo de estos gases provenían de la industria de la energía ${ }^{54}$.

Con el fin de fiscalizar el cumplimiento de las metas propuestas en la Política Energética, se implementaron políticas públicas concretas. Por ejemplo, a partir de una directriz del decreto supremo n. ${ }^{\circ} 148^{55}$, se han emitidos informes anuales de seguimiento para los años $2016^{56}, 2017^{57} \mathrm{y}$ $2018^{58}$. Además, el presidente Sebastián Piñera junto a la entonces ministra de Energía, Susana Jiménez, publicaron el programa "Ruta energética 2018-2022"59 ("Ruta"), la cual define una serie de ejes para el periodo de su gobierno al alero de la Política Energética ${ }^{60}$. Bajo el eje "energía baja en emisiones: hacia un mundo más limpio", la Ruta contemplaba uno de

${ }^{52}$ Política Energética, p. 71 y ss. Recientemente, el Ministerio de Energía adelantó la meta para el año 2030. Disponible en www.emol.com/noticias/Tecnologia/2019/12/10/969926/ Meta-70-energias-renovables-COP25.html [fecha de consulta: 1 de marzo de 2020].

${ }^{53}$ Política Energética, p. 80.

54 “Considerando que el sector energía contribuyó con el 75\% al total de emisiones del país en el año 2010, y que aproximadamente un 28\% de ese total proviene del sector de generación eléctrica, un 22,5\% de Transporte y un 13,5\% de Minería e Industria, los esfuerzos en mitigación de emisiones han de concentrarse en estos sectores. La implementación de un Plan de Mitigación de Emisiones centrado en estos sectores, permitirá reducir significativamente las emisiones de gases de efecto invernadero, y a su vez, complementar las demás acciones definidas para el sector que apuntan a un desarrollo energético sostenible, competitivo y seguro", op. cit., p. 79.

55 "El Ministerio de Energía será el encargado de liderar la implementación de la Política Nacional de Energía, realizar su seguimiento y realizar un informe anual de sus avances al Consejo de la Sociedad Civil del Ministerio de Energía”, art. 2 del decreto supremo n. ${ }^{\circ} 148$.

${ }^{56}$ Disponible en www.energia2050.cl/wp-content/uploads/2017/04/Informe-Seguimiento-2016.pdf [fecha de consulta: 6 de julio de 2019].

${ }^{57}$ Disponible en www.energia2050.cl/wp-content/uploads/2018/07/Informe-Seguimiento-2017.pdf [fecha de consulta: 6 de julio de 2019].

${ }^{58}$ Disponible en www.energia2050.cl/wp-content/uploads/2019/05/Informe-Seguimiento-2018-PEN.pdf [fecha de consulta: 6 de julio de 2019].

${ }^{59}$ Disponible en www.energia.gob.cl/rutaenergetica2018-2022.pdf [fecha de consulta: 17 de julio de 2019].

${ }^{60}$ La Ruta proponía siete ejes: modernización energética, energía con sello social, desarrollo energético, energía baja en emisiones, transporte eficiente, eficiencia energética y educación y capacitación energética (p. 12). 
los "megacompromisos" ${ }^{61}$ más ambiciosos y que más ha dado que hablar en el último tiempo: la descarbonización de la matriz eléctrica chilena ${ }^{62}$. Como veremos más adelante, la factibilidad de esta meta es consecuencia de la transformación del mercado eléctrico nacional que ha ocurrido en los últimos años.

\section{iii. Avances tecnológicos de la industria eléctrica}

La adecuación de la normativa eléctrica chilena junto con el impulso de buenas políticas públicas constituía el marco ideal para el desarrollo seguro, eficiente y renovable de nuestra matriz. Sin embargo, era indispensable que ello fuera de la mano con el factor tecnológico: la industria de la generación debía abaratar los elevados costos de inversión que acarreaban los proyectos ERNC, de modo de viabilizar la entrada de estas centrales y lograr así, poco a poco, una menor dependencia del sistema con relación a las generadoras convencionales, cuyo costo de desarrollo está muy ligado al precio y disponibilidad de los commodities. Esta circunstancia exponía al país a una constante incertidumbre.

Hacia el año 2010, el costo de desarrollo de centrales ERNC era elevado, por sobre, incluso, las centrales convencionales. Mientras que el prestigioso estudio "Projected Costs of Generating Electricity" de la Agencia Internacional de Energía proyectaba un costo normalizado de generación ("levelized cost of energy") sobre la base de ERNC por sobre los $400 \mathrm{USD} / \mathrm{MWh}^{63}$, la Irena señalaba que, para el mismo año, las licitaciones ERNC bordeaban los $250 \mathrm{USD} / \mathrm{MWh}^{64}$. Este índice de precios era precisamente una de las principales razones por las que las generadoras convencionales se resistían a la entrada masiva de $\mathrm{ERNC}^{65}$.

${ }^{61}$ Ruta, p. 14.

${ }^{62}$ Ibid.

${ }^{63}$ La estimación se refería a la generación solar. Disponible en www.oecd-nea.org/ ndd/pubs/2015/7057-proj-costs-electricity-2015.pdf [fecha de consulta: 17 de julio de 2019].

${ }^{64} \mathrm{El}$ precio licitado era en relación con la generación solar, IRENA (2017).

${ }^{65}$ Por ejemplo, un estudio apuntaba a que el cumplimiento de la meta propuesta por la Ley n. 20257 significaría para los consumidores del SIC a lo menos un costo de USD 4000000000 -traídos a valor presente en el año 2008-, al ser las centrales ERNC -generación con viento, se estimaba en ese entonces- cinco veces más caras que las convencionales, Galetovic y Muñoz (2008). Años más tarde, con relación al proyecto de ley 20/20 -que buscaba elevar los retiros mínimos sobre la base de ERNC al 20\% para el año 2020-, estudios nuevamente apuntaban a los elevados costos que supondría su aprobación: entre USD 443.000 .000 y USD 941.000.000 anuales. Véase el informe titulado "Matriz energética: la ceguera del proyecto de ley 20/20", preparado por Libertad y Desarrollo, de fecha 27 de enero de 2012, p. 4. Disponible en https://lyd. org/wp-content/uploads/2012/02/TP-1050-Matriz-Energetica-La-Ceguera-del-Proyectode-Ley-2020-27-01-2012.pdf [fecha de consulta: 3 de julio de 2019]. 
La evolución de la industria hacia 2015 y 2016 da cuenta de un progreso extraordinario. Las mismas consultoras antes citadas lo constataron, destacando, por ejemplo, que las licitaciones de generadoras solares bajaron hasta los $50 \mathrm{USD} / \mathrm{MWh}^{66}$ y que, de cara al futuro, las proyecciones tendrían una clara tendencia: mientras que el costo de desarrollo de las ERNC iría decayendo de manera permanente -hasta un 40\% más baratas al año 2040- las tecnologías convencionales mantendrían o elevarían sus $\operatorname{costos}^{67}$. Y los últimos estudios publicados han confirmado la tendencia, reflejando costos normalizados para centrales eólicas de gran escala por $29 \mathrm{USD} / \mathrm{MWh}$, y para solares por $36 \mathrm{USD} / \mathrm{MWh}^{68}$.

Esta transformación tecnológica ha repercutido claramente en los costos marginales y precios adjudicados en las licitaciones para distribuidoras. Sin embargo, sin las reformas legislativas y políticas públicas que se han introducido en los últimos diez años, no habría sido posible aprovechar estos menores costos de desarrollo ${ }^{69}$. En este sentido, si pretendemos

66 "In 2010, solar energy was contracted at a global average price of almost USD 250/ MWh, compared with the average price of USD 50/ MWh in 2016. Wind prices have also fallen, albeit at a slower pace (since the technology was more mature in 2010). The average price in 2016 was USD 40/MWh, down from USD 80/MWh in 2010", IrENA (2017), pp. 16-

28 17. De igual forma, el estudio de la Agencia Internacional de Energía reflejaba esta clara tendencia, señalando que, para 2015, el costo normalizado de generación ERNC había bajado a los 100 USD/MWh. Disponible en www.oecd-nea.org/ndd/pubs/2015/7057proj-costs-electricity-2015.pdf [fecha de consulta: 18 de julio de 2019].

67 "Policy preferences for lower carbon energy options are reinforced by trends in costs, as oil and gas gradually become more expensive to extract while the costs of renewables and of more efficient end-use technologies continue to fall”, IEA (2015), p. 26.

${ }^{68}$ LAZARD (2018). Los resultados del informe Irena (2018) son igual de auspiciosos: "New solar PV and onshore wind are expected to increasingly cost less than the marginal operating cost of existing coal fired power plants. In 2020, the weighted average PPA or auction price for solar PV from projects in the IRENA database -USD 0.048 per kilowatt-hour $(\mathrm{kWh})$ - is expected to be less than the marginal operating costs for around 700 gigawatts $(\mathrm{GW})$ of operational coal-fired capacity at the same time. Onshore wind -at USD $0.045 / \mathrm{kWh}$ - should fall below the marginal operating costs of almost $900 \mathrm{GW}$ of coal capacity potentially online in 2020”, p. 9. Autores han señalado que, además de los costos propios de las ERNC, se deben sumar otros "costos de integración" de estas centrales a la matriz eléctrica derivados de su carácter intermitente: costos de balance, de perfil y de transmisión, Clerc et al. (2017), p. 131 y ss.

${ }^{69}$ Véase, por ejemplo, RudNick (2011), donde a pesar del avance tecnológico de las ERNC, se advertía la existencia de barreras de entrada en el mercado chileno, como en el ámbito del financiamiento, transmisión y licitación. Además, en RAINERI (2018) se sostenía lo siguiente: "Los antecedentes aportados en este trabajo permiten concluir que el profundo proceso de transformación que ha venido experimentando la matriz energética en Chile se inicia, con fuerza, en el período 3/2010 -3/2014. Donde, las acciones de política y de perfeccionamiento del sector, más las señales emanadas desde el ejecutivo y de la ciudadanía, complementadas por las favorables condiciones de financiamiento y 
continuar profundizando la participación de ERNC en la matriz eléctrica -conforme se planifica en el Política Energética-, deberemos contar con una adecuada regulación sectorial que permita maximizar los beneficios y minimizar los costos que necesariamente conlleva su transformación ${ }^{70}$.

iv. Nuevo mercado eléctrico: costo de desarrollo sobre la base de energías renovables

Como hemos visto, cuando una robusta regulación normativa y sólidas políticas públicas se conjugan con un desarrollo industrial que permite reducir de forma drástica los costos de inversión y operación asociados a centrales ERNC, el costo de desarrollo del sistema muta desde su esquema tradicional, desplazando la construcción de nuevos proyectos sobre la base de energías convencionales. Es más, la interacción entre los participantes del mercado eléctrico también cambia sustancialmente, según explicaremos más adelante.

Así, podemos resumir la transformación del mercado eléctrico chileno a partir del año 2015, en virtud de dos factores empíricamente constatables:

(a) la explosión de la competencia con el ingreso de nuevos actores ERNC y

una fuerte reducción internacional en los costos de las energías renovables, como eólica y solar, llevaron a un drástico giro en el foco de desarrollo de proyectos de inversión, mudando a un fuerte crecimiento de las inversiones en proyectos de ERNC", pp. 1-2.

70 "La importancia de la robustez de la política es clave para no amenazar los objetivos de bienestar, crecimiento y productividad, por lo que cualquier iniciativa de fomento tecnológico debe realizarse con plazos prudentes de forma decidida, pero cuidadosa y gradualmente. Esto implica contar con tiempos adecuados que permitan que los agentes del sistema tengan holguras suficientes para hacer adecuaciones con anticipación y flexibilidad. Los ajustes inesperados o acelerados resultan costosos y afectan negativamente a la calidad y seguridad del servicio... Es de vital importancia que el principio de neutralidad tecnológica prime en el cumplimiento de metas ambientales y de mitigación de emisiones de gases de efecto invernadero. En ese sentido, los instrumentos que defina la política pública para reducir emisiones de carbono deben permitir que efectivamente el sistema se vaya adaptando a una configuración de mínimo costo que cambia con el progreso tecnológico, y sin presionar al alza los precios de la energía. Para ello, y antes de pensar en otras regulaciones que impongan nuevos costos al sistema de generación, es fundamental trasparentar los costos existentes y que se desprenden de la incorporación de generación intermitente", Clerc et al. (2017), pp. 213-214. "En el sector eléctrico, la inserción de energías renovables y nuevas tecnologías bajas en emisiones es la vía para reducir las emisiones de carbono, pero dicha inserción implicará múltiples cambios en el ámbito regulatorio para cumplir los objetivos de eficiencia y tarifas eléctricas competitivas a nivel global. Por lo señalado, resulta muy relevante la implementación de políticas públicas que generen incentivos a los agentes privados para converger al óptimo social, aquel que permita disponer de tarifas eléctricas competitivas para la industria local y consumidores finales", op. cit., p. 223. 
(b) la reducción sostenida de los precios en que se comercializa la energía.

\section{a. Diversificación de la oferta eléctrica}

La expansión de la oferta se puede analizar en distintos niveles. Con relación a la capacidad instalada, si en el año 2012 las ERNC contaban con una capacidad de tan solo 952 MW, a fines del año 2019 ascendía a 5322 $\mathrm{MW}^{71}$, siendo que la mayor parte de dicha capacidad se logró a partir del año 2015 en adelante ${ }^{72}$. En el ámbito de las licitaciones también se puede comprobar fácilmente la entrada de nuevos operadores: en los llamados 2015/01 y 2015/02 han resultado adjudicatarias más de diez nuevas generadoras, todas asociadas a energías renovables, mientras que la única central convencional adjudicataria fue Endesa ${ }^{73}$. A partir del proceso 2017/01, los cambios fueron aún más drásticos: el 100\% de la energía licitada (2 200 GWh anuales) correspondía a proyectos renovables ${ }^{74}$.

${ }^{71}$ Disponible en www.revistaei.cl/2019/12/23/energias-renovables-cerraran-2019con-mas-de-5-300-mw-de-proyectos-en-operaciones/ [fecha de consulta: 26 de diciembre de 2019]. "El porcentaje de las energías renovables en la matriz energética chilena se ha multiplicado por 5 desde 2012, y se espera que siga creciendo. Ya el pasado mes de octubre 30 se celebró que las ERNC fueran responsables del 20,2 \% de la generación de los SING y SIC, pues fue la primera vez que se superó el $20 \%$ en un mes.

En total, a lo largo del año alcanzaron una capacidad instalada de $4.895 \mathrm{MW}$, y el porcentaje total que representaron en la generación eléctrica fue del 20,3\%. De ese modo, la meta impuesta por ley de que en 2025 al menos el $20 \%$ de la generación del país proviniera de fuentes limpias se alcanzó con ocho años de antelación”, artículo de prensa "El 83\% de la nueva energía en operación en 2018 chile será renovable". Disponible en www.pv-magazine-latam.com/2018/02/06/el-83-de-la-nueva-energia-en-operacion-en2018-chile-sera-renovable/ [fecha de consulta: 19 de agosto de 2019].

${ }^{72}$ En la industria solar, por ejemplo, a 2013 existía apenas una capacidad de $12 \mathrm{MW}$, para crecer aceleradamente a una tasa de 255\% anual hasta llegar a los 1914 MW a fines de 2017. Fuente: "Futuro Renovable: estudio escenarios de inserción de energías renovables", de Generadoras de Chile, p. 16. Disponible en http://generadoras.cl/media/ pagefiles/447/180515\%20Presentaci\%C3\%B3n\%20Generadoras\%20Proyecta $\% 20$ Solar $\% 20$ Chile\%20Latam\%202018.pdf [fecha de consulta: 20 de agosto de 2019].

${ }^{73}$ Así, el $52 \%$ de la energía licitada en dichos procesos fue adjudicada a centrales ERNC, lo que corresponde a casi 8.000 GWh anuales. CNE (2017), pp. 80-82.

${ }^{74}$ Artículo de prensa "Licitación eléctrica: las claves del proceso que marcó un 'nuevo hito' en el sector". Disponible en www.emol.com/noticias/Economia/2017/11/03/881762/ Nuevo-hito-en-el-sector-marcan-adjudicaciones-electricas-2017-con-un-precio-promediode-325-usdmwh-y-100-de-renovables.html [fecha de consulta: 20 de agosto de 2019]; Artículo de prensa "Los planes de los ganadores de la licitación suministro 2017". Disponible en www.revistaei.cl/reportajes/los-planes-los-ganadores-la-licitacion-suministro-2017/\# [fecha de consulta: 20 de agosto de 2019]; Acta de adjudicación licitación 2017-1. Disponible en www.licitacioneselectricas.cl/wp-content/uploads/download-manager-files/ActaAdjudicacion-Oferta-Economica.pdf [fecha de consulta: 20 de agosto de 2019]. 
Finalmente, con relación con los proyectos de generación que están en construcción, se puede apreciar el reinado de centrales renovables: casi todas las unidades en construcción son plantas solares, eólicas y minihidráulicas ${ }^{75}$, llegando hacia 2019 a más de un $90 \%$ de los proyectos existentes $^{76}$. Esta realidad llevó a las principales empresas generadoras -Engie, Enel, AES Gener y Colbún- a acordar un programa de cierre de todas las plantas a carbón existentes en el país, en etapas escalonadas hasta $2040^{77}$.

\section{b. Hundimiento de los precios de energía}

Históricamente, podemos apreciar una gran volatilidad de los precios de la energía en nuestro mercado eléctrico, con crecidas y bajadas constantes a lo largo del tiempo. Y, si bien han existido épocas donde los precios han alcanzado cierta estabilidad y han presentado niveles accesibles a los consumidores -como durante el periodo 2002-2005, donde se veían precios estables promediando los $30 \mathrm{USD} / \mathrm{MWh}$ en el SIC y SING ${ }^{78}-$, ello se ha explicado por situaciones más coyunturales que estructurales, como los bajos precios de ciertos commodities $^{79}$. La poca diversidad de oferentes durante estos periodos son una muestra de ello.

${ }^{75}$ Resolución exenta n. ${ }^{\circ} 58$ de la CNE, de fecha 31 de enero de 2018. Disponible en www.cne.cl/archivos_bajar/RES_EX_CNE_58_2018.pdf [fecha de consulta: 20 de agosto de 2019].

${ }^{76}$ Artículo de prensa "Los proyectos que debutan este 2019". Disponible en http:// generadoras.cl/prensa/los-proyectos-que-debutan-este-2019 [fecha de consulta: 20 de agosto de 2019]; véase resolución exenta n. ${ }^{\circ} 187$ de la CNE. Disponible en www.cne.cl/wpcontent/uploads/2015/05/Resolución-Exenta-N $187 \_20-02-2019 . p d f$ [fecha de consulta: 20 de agosto de 2019]; véase resolución exenta n. ${ }^{\circ} 323$ de la CNE. Disponible en www. cne.cl/wp-content/uploads/2019/06/Res.-Ext.-N\%C2\%B0323_23-05-2019.pdf [fecha de consulta: 20 de agosto de 2019].

${ }^{77}$ Artículo de prensa "Presidente Piñera presenta plan para cerrar todas las centrales energéticas a carbón y que Chile sea carbono neutral". Disponible en www.msgg.gob. cl/wp/index.php/2019/06/04/presidente-pinera-presenta-plan-para-cerrar-todas-lascentrales-energeticas-a-carbon-y-que-chile-sea-carbono-neutral/ [fecha de consulta: $20 \mathrm{de}$ agosto de 2019].

${ }^{78}$ Ministerio de Minería, Comisión Chilena del Cobre, "Análisis histórico de los precios de energía eléctrica en minería y su impacto en competitividad”, p. 8. Disponible en www.cochilco.cl/Listado $\% 20$ Temtico/Analisis $\% 20$ Historico $\% 20 \mathrm{de} \% 20$ Precios $\% 20$ de $\% 20 \mathrm{EE} \% 2024-12-2014 \% 20$ vf.pdf [fecha de consulta: 20 de agosto de 2019].

${ }^{79}$ Véanse los bajos precios del gas en el periodo entre los años 2000 a 2006, previo al recorte de las importaciones desde Argentina, en la figura 18 de Ministerio de Minería, Comisión Chilena del Cobre, "Análisis histórico de los precios de energía eléctrica en minería y su impacto en competitividad", p. 18. Disponible en www.cochilco.cl/Listado\%20 Temtico/Analisis $\% 20$ Historico $\% 20 \mathrm{de} \% 20$ Precios $\% 20 \mathrm{de} \% 20 \mathrm{EE} \% 2024-12-2014 \% 20 \mathrm{vf.pdf}$ [fecha de consulta: 20 de agosto de 2019]. 
En cambio, la situación actual da cuenta de un verdadero cambio estructural a partir de la diversificación de la oferta eléctrica propiciada por cambios regulatorios y menores costos asociados a las tecnologías empleadas en la construcción y operación de centrales, lo que ocasionó, a su vez, un progresivo decaimiento de los precios de la energía. Con relación al precio spot, si en los años 2011-2012 los costos marginales superaban los $250 \mathrm{USD} / \mathrm{MWh}$ para el nudo Alto Jahuel (nudo central del sistema), hacia los años 2016-2017 se hundían por debajo de los $50 \mathrm{USD} / \mathrm{MWh}^{80}$, con un leve repunte el año $2018^{81}$. Misma tendencia podemos observar en los precios adjudicados en licitaciones de suministro eléctrico, donde en el año 2012 las ofertas adjudicadas superaban los $130 \mathrm{USD} / \mathrm{MWh}^{82}$, pero en el año 2017 bordeaban los $30 \mathrm{USD} / \mathrm{MWh}^{83}$.

Proyectar cuál será el nivel de costos marginales que existirá en el futuro es una tarea difícil. A partir de la propia volatilidad del mercado spot, la experiencia indica que, en nuestro país, dichas proyecciones pocas veces se han cumplido en la realidad. Sin embargo, como adelantábamos, la transformación del mercado chileno que ha venido gestándose en los últimos años obedece a cambios estructurales que permiten proyectar, posiblemente con cierto grado mayor de certeza, cuál será el comportamiento futuro de los costos marginales. En este sentido, conforme al último Informe técnico definitivo de la CNE para la fijación de precios de nudo de corto plazo, la autoridad proyectó que hacia el año 2024, los precios de la energía promediarían los $33 \mathrm{USD} / \mathrm{MWh}$ aproximados ${ }^{84}$.

\section{AJuste y REVISIÓN DE CONTRATOS \\ EN EL NUEVO ESCENARIO ELÉCTRICO}

Debido a la transformación estructural del mercado eléctrico que hemos señalado y a su funcionamiento por orden de mérito, el sistema se ha ido

${ }^{80} \operatorname{SYSTEP}(2016 \mathrm{a})$, p. 26.

${ }^{81}$ Systep (2018), p. 21.

${ }^{82}$ Véase tabla 10, CNE (2017), p. 85.

${ }^{83}$ Véase Acta de adjudicación oferta económica. Primera etapa, licitación de suministro 2017/01. Disponible en www.cne.cl/wp-content/uploads/2016/12/Acta-Adjudicaci $\%$ C3\%B3n-Oferta-Econ $\%$ C3\%B3mica.pdf [fecha de consulta: 20 de agosto de 2019]; Artículo de prensa "Valor de la energía más bajo en la historia de las licitaciones en Chile". Disponible en www.cne.cl/prensa/prensa-2017/11-noviembre-2017/valor-de-la-energia-masbajo-en-la-historia-de-las-licitaciones-en-chile/ [fecha de consulta: 17 de agosto de 2019].

${ }^{84}$ Precio proyectado para la barra Quillota en la Fijación de precios de nudo de corto plazo, informe técnico definitivo de la CNE, enero de 2020, p. 45. Disponible en www. cne.cl/wp-content/uploads/2020/01/ITD-PNCP-Ene20.pdf [fecha de consulta: 3 de marzo de 2020]. 
ajustando a las tecnologías más eficientes -como plantas solares y eólicas-, desplazando a las centrales convencionales que, años atrás, reinaban la capacidad instalada de nuestra matriz. Este efecto se ha producido con particular intensidad en la zona norte de nuestro país, donde abunda energía renovable, causando que centrales convencionales -como termoeléctricasque antes se encontraban despachadas, han debido restringir bastante su funcionamiento a mínimos técnicos, esto es, al mínimo nivel de despacho en que una central puede funcionar de manera estable y segura ${ }^{85}$.

Sin embargo, debido a la intermitencia de las ERNC - e.g. los parques solares funcionan en las horas diurnas y la generación eólica experimenta grandes oscilaciones durante diferentes horas del día y del año-, el Coordinador debe reordenar constantemente el despacho de las centrales a lo largo del día y en periodos muy cortos, despachando a las centrales convencionales disponibles, produciéndose el fenómeno conocido como cycling: operación de centrales con constantes encendidos y apagados ${ }^{86}$. Así, las centrales convencionales han dejado de ser centrales de base para convertirse en unidades de respaldo de las ERNC. Si bien el cycling es una característica que se daba en las centrales desde antes de la entrada de generadoras renovables, su presencia era mucho menor y estaba asociada a variaciones en el perfil de carga de los consumidores finales ${ }^{87}$.

85 "El mínimo técnico que es declarado para una central generadora se basa en una serie de aspectos técnicos de distinta naturaleza. Así, la definición debe asegurar a la central operar en el menor nivel de despacho posible de manera segura, estable y, eventualmente, en forma permanente, cumpliendo siempre todas las restricciones que imponen las distintas regulaciones aplicables a estas instalaciones", artículo de prensa "Los mínimos técnicos de las centrales generadoras". Disponible en www.revistaei.cl/columnas/los-minimos-tecnicos-de-las-centrales-generadoras/ [fecha de consulta: 2 de julio de 2019].

86 "Un aspecto inherente en las inyecciones de energía de las fuentes ERNC, en especial las solares y eólicas, es la variabilidad e incertidumbre de sus recursos energéticos primarios que impactan directamente en la operación del sistema, en especial en las unidades termoeléctricas convencionales. Esto implica un mayor requerimiento ciclos de encendido/apagado durante las noches y detenciones durante el día (cycling), lo que podría traducirse en un aumento de los costos variables no combustibles (CVNC) para estas plantas", SYSTEP (2016b), p. 2.

${ }^{87}$ Artículo de prensa "La implicancia del cycling en centrales termoeléctricas". Disponible en http://generadoras.cl/prensa/la-implicancia-del-cycling-en-centrales-termoelectricas [fecha de consulta: 6 de agosto de 2019]; "Si bien, es esperable que la incorporación de un bloque de energía de bajo costo permita disminuir el costo global de operación resultante del pre-despacho, esta integración modifica el régimen operativo de las unidades convencionales, aumentando el movimiento de unidades y principalmente el número de partidas/detenciones, pudiendo algunas unidades de ciclo de combinado a gas natural tener una partida y detención diaria en los meses de verano para los escenarios de mayor integración. El régimen de partidas/detenciones de los generados a gas natural, fenómeno denominado en la literatura como 'Cycling', aumenta como resultado de la interacción de los perfiles ERNC estudiados con el parque generador convencional, lo 
Luego de la entrada masiva de ERNC, el cycling se ha convertido en un componente estructural en el funcionamiento de muchas termoeléctricas ${ }^{88}$, lo que ha despertado la preocupación de las generadoras convencionales que han visto reducidos sus ingresos como consecuencia de una menor remuneración del mercado spot ${ }^{89}$.

Este nuevo esquema de funcionamiento no le trae problemas exclusivamente a las generadoras, sino que, además, a los clientes que suscribieron años atrás contratos de suministro eléctrico de largo plazo bajo una estructura de funcionamiento diferente a la que ocurre hoy, la que recogía los términos y obligaciones pactados en los PPA. Esta situación se produce debido a que, como explicábamos, las generadoras deben salir a comprar en el mercado spot la energía que venderán a sus clientes al precio pactado en sus respectivos contratos. Luego, como consecuencia de la entrada masiva de centrales eficientes y que los costos marginales han caído fuertemente, se produce una gran diferencia entre el precio spot, que es soportado por la generadora y el precio de la energía pactada en los contratos de suministro, que es soportado por el cliente.

$\mathrm{Si}$ a esta circunstancia le sumamos el fenómeno del cycling $^{90}$, en virtud del cual las generadoras convencionales ven restringida de manera constante su inyección y funcionamiento, el desequilibrio que se produce en

que se traduce en encendidos de estas unidades durante la noche y detenciones durante el día”, CDEC-SING (2015), p. 7.

${ }^{88}$ Por ejemplo, la central termoeléctrica Guacolda tiene, en promedio, nueve horas a mínimo técnico en cada ciclo, Systep (2017), p. 17. Centrales térmicas operadas por Engie y por Enel también evidencian cycling continuo. Véase artículo de prensa "Industria advierte trabas para operar centrales térmicas”. Disponible en www.revistaei.cl/2016/11/22/industria-advierte-trabas-para-operar-centrales-termicas/ [fecha de consulta: 9 de agosto de 2019].

89 "Al respecto, en el sector ha aumentado la preocupación por el cycling-constante encender y apagar de las unidades térmicas para cubrir los períodos en que las ERNC no están aportando- al que se está exponiendo a este parque, sobre todo en zonas como el Sistema Interconectado del Norte Grande (SING) y en el norte del Sistema Interconectado Central (SIC), que es donde más participación tienen las ERNC. Este fenómeno no sólo trae problemas técnicos al acelerar el fin de la vida útil de las turbinas, sino que también reduce los ingresos que generan las centrales al bajar su participación en la producción eléctrica”, artículo de prensa "Industria advierte trabas para operar centrales térmicas". Disponible en www.revistaei.cl/2016/11/22/industria-advierte-trabas-para-operar-centrales-termicas/ [fecha de consulta: 9 de agosto de 2019]. Como consecuencia de la entrada permanente de energía ERNC al sistema, el Coordinador ha debido ir reduciendo los mínimos técnicos de las centrales. Véase artículo de prensa "Mínimos técnicos de termoeléctricas se redujeron en 1.411 MW". Disponible en www.revistaei.cl/informes-tecnicos/minimostecnicos-termoelectricas-se-redujeron-1-411-mw/\# [fecha de consulta: 9 de agosto de 2019].

${ }^{90}$ Usualmente, se pacta en los contratos de suministro que el costo asociado a la operación a mínimo técnico lo soporta el cliente. 
los contratos de suministro puede ser aún más perjudicial para los clientes, pues las centrales, en definitiva, se limitarán en muchas horas del día a comprar energía barata y renovable sin tener que asumir los costos variables que significaría producir la energía (pues su operación es desplazada en orden de mérito por centrales ERNC). Así, el desajuste económico se agrava por el hecho de que la generadora recibe un precio contractual que incorporaba, entre otros componentes, los costos variables que significaría producir la energía vendida, pues estos contratos se celebraban bajo un esquema eléctrico en que las centrales convencionales estarían permanentemente despachadas. Sin embargo, hoy muchas generadoras no se encuentran en la necesidad de incurrir en dichos costos variables en la medida que "retiran" energía producida por generadoras renovables.

En definitiva, el desequilibrio contractual comentado se produce por la disociación entre

(i) las condiciones esperadas en el mercado de contratos antes de la entrada masiva de ERNC (i.e. situación previa al 2015), y en virtud de las cuales se suscribieron contratos de suministros que recogían dichas expectativas, con

(ii) los cambios que ocurrieron y llevaron a que el mercado spot presentara condiciones imprevistas.

Frente a esta realidad, se ha observado en la industria que muchos contratos de suministro han sido modificados luego de un proceso de negociación, de modo de ajustar los precios de energía hacia niveles más cercanos a los que presenta el mercado spot hoy ${ }^{91}$.

En el ámbito de contratos regulados, el conflicto más conocido se relaciona con la situación de la central El Campesino, proyecto con el cual Generadora Metropolitana se adjudicó bloques de suministro en la licitación del año 2014 a un precio que se ajustaba a las condiciones de mercado de esa época: 110 USD/MWh. Sin embargo, la central nunca se construyó, aun cuando el contrato licitado entró en vigencia a comienzos del año 2019, limitándose Generadora Metropolitana a participar de los balances del Coordinador con costos marginales mucho más atractivos para abastecer los bloques adjudicados ${ }^{92}$.

${ }^{91}$ En este sentido, María Isabel González, exsecretaria ejecutiva de la CNE, señaló lo siguiente: "Muchos clientes que ya tienen la condición de clientes libres, pero tienen contratos a precios muy altos por la realidad del mercado, y como en general son contratos de largo plazo -8 o 10 años-, muchos se están acercando a sus proveedores, algunos de los cuales ha estado abierto a reconocer que las condiciones del mercado han cambiado, por lo que les ofrecen descuentos en el precio a cambio de alargar un poco el contrato", artículo de prensa "Sector minero aplica ampliación de contratos eléctricos para negociar precios". Disponible en www.revistaenergia.com/?p=9489 [fecha de consulta: 9 de agosto de 2019].

${ }^{92}$ Artículo de prensa "Ministerio de Energía estudia invalidar contrato de suministro eléctrico con El Campesino”. Disponible en www.revistaei.cl/2019/03/13/ministerio-ene- 
Así como ha ocurrido en el último tiempo con la entrada agresiva de ERNC, la historia del mercado eléctrico chileno ha evidenciado otros procesos o coyunturas que han impactado su funcionamiento y los contratos de suministro. Basta con remitirse a la crisis ocasionada por el corte del suministro del gas desde Argentina, ocurrida en el año 2006, en la cual se dio una situación inversa a la actual: los costos variables de la energía incrementaron notablemente, de modo que muchos PPA que habían sido suscritos con anterioridad vieron afectado su equilibrio en desmedro de las centrales ${ }^{93}$.

Sin perjuicio de que, de cara al futuro y por las razones que hemos explicado más atrás, se espera un mercado eléctrico estructurado a partir de energías renovables, nada asegura que ello ocurra. Como hemos visto, nuestro sistema presenta una volatilidad continua y, en ciertas ocasiones, imprevista. Y, si bien las ERNC nos permiten lograr una generación eléctrica eficiente, sustentable y a bajo costo, presentan una serie de desafíos en el ámbito operacional que ya han sido advertidos en la industria y que podrían ocasionar nuevas alteraciones al mercado spot o al mercado de contratos $^{94}$.

Con relación al mercado de contratos de suministro, frente al desequilibrio económico de los derechos y obligaciones contenidos en ellos como 36 consecuencia del acaecimiento de eventos imprevistos, se ha planteado en Chile la posibilidad de revisar el contrato aplicando la teoría de la imprevisión. Sin embargo, debido a la falta de respaldo legal expreso que consagre dicha teoría y frente a la ocurrencia cada vez más usual de conflictos contractuales derivados de situaciones imprevistas, se han ido incorporando cláusulas de ajuste o revisión de contrato, conocidas estas últimas como cláusulas hardship. A continuación, analizaremos por separado cada una de estas vías de modificación contractual, al alero del estado actual del mercado eléctrico, de la doctrina y la jurisprudencia.

rgia-estudia-invalidar-contrato-suministro-electrico-campesino/ [fecha de consulta: 12 de agosto de 2019]. Finalmente, la controversia fue solucionada a partir de un acuerdo celebrado entre Generadora Metropolitana y la CNE. Artículo de prensa "El Campesino y gobierno logran acuerdo: firma instalará $600 \mathrm{MW}$ renovables". Disponible en http:// generadoras.cl/prensa/el-campesino-y-gobierno-logran-acuerdo-firma-instalara-600-mwrenovables [fecha de consulta: 12 de agosto de 2019].

${ }^{93}$ En este contexto, GasAtacama estuvo al borde de la quiebra entre los años 2007 y 2008 a partir del aumento de sus costos frente al término del suministro de gas argentino, debiendo reemplazarlo por diésel. Véase artículo de prensa "GasAtacama. El renacer de uno de los pilares del SING". Disponible en https://issuu.com/electricidad/docs/ electricidad_116 [fecha de consulta: 12 de agosto de 2019].

${ }^{94}$ CleRC et al. (2017), capítulo 7. 


\section{A. Teoría de la imprevisión}

Ante la alteración de las circunstancias vigentes al momento de celebrar un contrato, de modo completamente imprevisible para las partes, la teoría de la imprevisión se presenta como la clásica excepción al principio de la fuerza obligatoria de los contratos -recogido en la locución pacta sunt servan$d a-$, que habilita a las partes a revisar e, incluso, a terminar sus acuerdos ${ }^{95}$.

Para su aplicación, esta teoría requiere que el cumplimiento de la obligación por parte del deudor se vuelva excesivamente onerosa a causa de circunstancias imprevistas ${ }^{96}$. El fundamento de ello se ha encontrado, por lo general, en la cláusula rebuc sic stantibus ${ }^{97}$, que se entiende incorporada en todo contrato conmutativo y de tracto sucesivo, y en virtud de la cual la obligatoriedad del vínculo contractual pende de la invariabilidad de las circunstancias que las partes tuvieron en consideración al momento de contratar ${ }^{98}$.

La procedencia de esta teoría en el contexto de imprevistos ocurridos en el mercado eléctrico tiene un triple desafío. Primero, cabe preguntarse si la variación del mercado spot puede considerarse como un supuesto de excesiva onerosidad sobrevenida, en clave de teoría de la imprevisión. Básicamente, corresponde determinar si existe un perjuicio de competitividad o costo de oportunidad para el adquiriente, cuando el costo marginal decrece y pierde la oportunidad de ser suministrado a un precio muy inferior por un "hecho sobreviniente" (i.e. la reestructuración del mercado eléctrico). En este caso, si bien estrictamente al comprador no le es más "oneroso" cumplir con su obligación con relación a los términos pactados, el avalúo de la prestación del vendedor se ha visto afectado por circunstancias sobrevinientes $y$, en consecuencia, el contrato ha perdido su equilibro.

Segundo, nuestro derecho no contempla una regla expresa que habilite al juez a revisar los términos de los contratos con el propósito de adecuarlo a las nuevas circunstancias, a diferencia de la legislación comparada ${ }^{99}$. Por

${ }^{95}$ Corral (2010), p. 241.

${ }^{96}$ Peñailillo (2000), p. 221.

${ }^{97}$ El origen de dicha cláusula la encontramos en los posglosadores, quienes la perfilaron del siguiente modo: "contractus qui habent tractus sucessivus vel dependencia de futuro rebus sic stantibus intelliguntur", específicamente, Baldo de Ubaldis al comentar el Digesto (12.4.8). Véase Gordley y Von Mehren (2006); Zimmermann (1990), pp. 581-582.

${ }^{98}$ Momberg (2010a), p. 45; Puig (1976), p. 392 y ss.

${ }^{99}$ Por ejemplo, los arts. 6:258 del Código Civil holandés y 313 del Código Civilalemán la recogen expresamente. También se encuentra regulada en los códigos civiles italiano y argentino con relación a contratos unilaterales onerosos, en los arts. 1468 y 1198 , respectivamente. A su vez, los Principios Lando de derecho contractual europeo y los Principios Unidroit de Contractos Comerciales Internacionales la contemplan en sus arts. 2.117 (2) y 6.2 .2 y 6.2 .3 , respectivamente. 
este motivo, existe una división actual en la doctrina nacional: parte de ella ha sido reticente a adoptar la teoría en la medida en que no se regule su aplicación ${ }^{100}$. Pero, por otro lado, existen autores que entienden que nuestra legislación, implícitamente, recoge esta doctrina ${ }^{101}$, por lo que se abren a su aplicación en Chile.

Por último, tampoco existe uniformidad en el ámbito jurisprudencial. Nuestros tribunales civiles han tendido a rechazar el reconocimiento explícito de esta teoría ${ }^{102}$. Sin embargo, en materia arbitral la situación es más incierta, pues existen fallos que se pronuncian a favor ${ }^{103} \mathrm{y}$ otros en

Cabe señalar que en Chile han existido iniciativas que no han tenido o, bien, aún no tienen éxito, para incorporar normativamente la teoría de la imprevisión. En efecto, con fecha 6 de diciembre de 2017, el senador Carlos Bianchi Chelech presentó la moción denominada "Para introducir un artículo nuevo en el Código Civil para regular la imprevisión contractual" (Boletín, n. ${ }^{\circ} 11532-07$ ), la cual se encuentra desde el 12 de diciembre del 2017 en la Comisión de Constitución, Legislación, Justicia y Reglamento. Dicha moción buscó introducir en el Código Civilel art. 1545 (bis), en los siguientes términos: "No obstante lo establecido en el artículo anterior, si la ejecución de las prestaciones emanadas de la obligación estipulada en los contratos onerosos, conmutativos y de tracto sucesivo o a plazo, se torne exorbitantemente más onerosa, cualquiera de los contratantes podrá ocurrir ante el tribunal competente, para que efectúe un llamado a conciliación, a fin de que las partes adecuen de común acuerdo las cláusulas contractuales a las nuevas circunstancias imperantes, o en su defecto, convengan la terminación o resciliación del contrato.

Se entenderá que la ejecución de las prestaciones emanadas de la obligación se ha tornado exorbitantemente más onerosa, cuando aquélla importe un cumplimiento en más del doble del valor de la obligación pactada.

En caso de que no se produjere acuerdo, en los términos del inciso primero, el tribunal adoptará las medidas que estime convenientes para restablecer la equidad de las prestaciones, en procedimiento breve y sumario".

${ }^{100}$ De la Maza (2009); Abeliuk (2003), p. 763; Peñailillo (2000), p. 209 y ss.; Caprile, (2007), p. 141 y ss. Para ver una visión sobre la conveniencia en términos de seguridad jurídica, véase MOMberg (2010b), p. 29 y ss.

${ }^{101}$ DörR (1988), pp. 253-270; Illanes (2000), pp. 221-225.

${ }^{102}$ Corral (2010), p. 245; Corte Suprema, sentencia de fecha 9 de septiembre de 2009, rol n. ${ }^{\circ}$ 2651-2008. Sin embargo, han existido pronunciamientos implícitos en favor de ella: Corte de Apelaciones de Santiago, sentencia de 20 de diciembre de 1984, Repertorio, T. 81, sección $2^{\mathrm{a}}$, p. 147. Un reconocimiento explícito lo encontramos en Corte de Apelaciones de Santiago, "Guillermo Larraín Vial con Servicio de Vivienda y Urbanización de la Región Metropolitana” (2006), comentada por AlCalde (2007), pp. 361-372. Una visión contraria en Momberg (2008).

${ }^{103}$ Sentencia del árbitro arbitrador Carlos Urenda Zegers, "Sociedad Inversiones Mónaco Limitada c/ el Consejo de Administración de la misma”, en AlCalde (2018), pp. 152-153; sentencia del árbitro mixto Claudio Illanes Ríos, "EMOS c/ Sociedad Constructora La Aguada Limitada", en AlCALde (2018), pp. 153-154 y sentencia del mismo árbitro, en proceso caratulado "Empresa Eléctrica Guacolda S.A. c/ Empresa Minera Mantos Blancos S.A.”, de fecha 25 de abril de 2007. Dicha sentencia es comentada por el mismo árbitro en IlLANES (2000), p. 202 y ss.; sentencia del árbitro en derecho Juan Carlos Dörr Zegers, "E.M. DE M.B. S.A. (XXX) c/ E.E. DEL N.G. S.A. (ZZZ)”, de fecha 25 de 
contra. Esta contradicción se da con mayor preocupación en el ámbito del mercado eléctrico, pues existen dos decisiones opuestas en sede arbitral cuya situación fáctica era idéntica: la crisis del gas con Argentina. En ambos casos, las empresas generadoras buscaron terminar o modificar sus respectivos PPA alegando que el corte del suministro constituía un hecho inesperado e imprevisible que tornó sumamente oneroso el cumplimiento de sus acuerdos comerciales ${ }^{104}$. Ello dio paso para que los actores encuadraran sus pretensiones bajo el alero de la teoría de la imprevisión.

En el primero de estos juicios, caratulado Gas Atacama Generación S.A. c/ Empresa Eléctrica de Antofagasta S.A., el árbitro Ricardo Peralta Valenzuela determinó que el incumplimiento por parte de Argentina al Protocolo de integración gasífera entre Chile y Argentina, del año 1995, no importaba un cambio imprevisto que convirtiera excesivamente onerosa la obligación de la generadora, ya que equivaldría a señalar que su obligación sería suministrar energía y potencia utilizando el gas como combustible, cuestión que no se adecúa a lo pactado y obvia la sofisticación de las partes involucradas y la magnitud de la inversión encuadrada bajo el PPA ${ }^{105}$. Sin embargo, en el segundo caso caratulado Empresa Eléctrica Guacolda S.A. con Empresa Minera Mantos Blancos S.A., el juez árbitro Claudio Illanes Ríos entendió que la "crisis del gas" era un cambio imprevisto de circunstancias que afectó la estructura del mercado eléctrico, procediendo a revisar el precio del PPA respectivo con el propósito de morigerar el desequilibrio contractual que dicho evento gatilló ${ }^{106}$.

Esta evidente contradicción en la resolución de casos similares ocasiona una falta de predictibilidad de las decisiones judiciales, poniendo en tela de juicio las aspiraciones sistémicas de seguridad jurídica. Sin embargo, es un síntoma, a su vez, del estado actual de la discusión que se ha dado tanto en doctrina como jurisprudencia: la falta de consenso.

Ahora bien, aun considerando la incertidumbre que existe en Chile respecto de la teoría de la imprevisión, ella se presenta como una posibilidad para ajustar los PPA suscritos en ausencia de cláusulas de ajuste de precio

septiembre de 2000, disponible en www.camsantiago.cl/sentencias/indice_materias.html [fecha de consulta: 17 de agosto de 2019]. En contra, encontramos las sentencias del árbitro arbitrador Luis Simón Figueroa del Río, "XX c/ ZZ S.A.”, de fecha 4 de diciembre de 2003 y "XX con ZZ", de fecha 11 de noviembre de 2009, disponible en www.camsantiago. cl/sentencias/indice_materias.html [fecha de consulta: 17 de agosto de 2019]. Una visión de la forma en que ha fallado la Contraloría General de la República la encontramos en Alcalde (2018), pp. 161-163.

${ }^{104}$ Momberg (2011), p. 4 y ss.

${ }^{105}$ Bahamondez (2008), p. 387.

${ }^{106}$ Sentencia del árbitro Claudio Illanes Ríos, "Empresa Eléctrica Guacolda S.A. con Empresa Minera Mantos Blancos S.A.”, de fecha 25 de abril de 2007. 
o hardship. De hecho, ninguno de los contratos de suministro, objeto de los dos arbitrajes mencionados, contenía cláusula de revisión de precios. Sin embargo, la transformación del mercado eléctrico ocurrida a partir de la entrada masiva de ERNC, ha cambiado la lógica negocial de los PPA, lo que ofrece una oportunidad para la incorporación de nuevas técnicas de redacción de cláusulas que busquen mantener la conmutatividad del contrato, evitando incertidumbres asociadas a una falta de consenso en la aceptación de la teoría de la imprevisión. Como veremos, este nuevo camino debe aspirar a ser armónico con un interés primordial que las partes buscan al suscribir contratos de suministro eléctrico: sustraerse de la incertidumbre del mercado spot.

\section{B. Técnicas empleadas en contratos de suministro eléctrico regulados}

En el ámbito de los contratos de suministro celebrados entre distribuidoras y generadoras, nuestra regulación ha ido reaccionando frente a las coyunturas imprevistas que han impactado al sistema eléctrico, incorporando disposiciones en aras de velar por la conmutatividad pactada en dichos contratos. En este sentido, nos referiremos a dos situaciones que involucraron cambios diametralmente opuestos en las estructuras de los contratos regulados.

La primera regulación nació como consecuencia de la crisis del gas argentino, la que provocó dos tipos de reacciones en nuestro país: una inmediata, en que las centrales existentes que se vieron desprovistas de suministro comenzaron a reemplazarlo por diésel; y otra mediata, relacionada con la realización de proyectos de construcción de centrales a carbón. Sin embargo, el gran obstáculo para estos proyectos se producía por la incertidumbre de las generadoras en torno a la evolución de los precios y la tecnología que se emplearía en el futuro. En estas circunstancias, no existían condiciones idóneas para promover exitosamente procesos de licitación de distribuidoras, pues los precios que se establecían hasta ese entonces en los contratos regulados estaban basados en los Precios Nudos de Corto Plazo calculados para cada semestre por la CNE, los cuales:

"buscaban reflejar un promedio en el tiempo de los costos marginales de suministro a nivel generación-transporte para usuarios de muy bajo riesgo" 107 .

${ }^{107}$ Rozas (2016), p. 19. 
La historia de la Ley Corta II, refleja esta incertidumbre que existía en el mercado eléctrico ${ }^{108}$ y que, a través de su promulgación, pretendía eliminarse mediante la existencia de un proceso de licitación que se guiara por la oferta y demanda de energía, de modo que los precios de los contratos regulados fueron un producto de dicha interacción y se mantuvieran inalterables durante toda la vigencia de los contratos adjudicados ${ }^{109}$, con independencia de lo que ocurriese con los costos marginales.

Si bien mediante la Ley Corta II las generadoras ganaron en seguridad jurídica, pues sabían con anterioridad a la suscripción del contrato o antes de la construcción de una central, cuál sería el precio que recibirían por la venta de energía, existían otras circunstancias externas que podían aún mermar la conmutatividad del contrato y que fueron ocurriendo con posterioridad a la dictación de dicha ley: la existencia de cambios regulatorios. Por ejemplo, la Ley n. ${ }^{\circ} 20780$ del año 2014, que impactó los costos de las generadoras mediante un tributo que gravaba la emisión de gases nocivos ${ }^{110}$.

La Ley n. 20805 buscó proteger a las generadoras frente a la ocurrencia de estas circunstancias imprevistas, consagrando un mecanismo de revisión de precios en los contratos de suministro licitados que puede activarse si se cumplen los siguientes requisitos ${ }^{111}$ :

a. Circunstancia imprevista: existencia de cambios sustanciales y permanentes en la regulación eléctrica o tributaria.

b. Onerosidad y causalidad: los costos de capital o de operación para la ejecución del contrato deben haber variado como consecuencia

108 "En lo que respecta al desarrollo de inversiones eléctricas, la situación actual muestra un mercado altamente interesado en ampliar la oferta por las buenas perspectivas de la demanda, pero con fuertes dudas de tipo económico y tecnológico frente a la incertidumbre externa que enfrenta nuestro mercado de gas natural. Esta incertidumbre se manifiesta en la imposibilidad de predecir la evolución de los precios, tanto libres como regulados, para el largo plazo, dado que se desconoce si la realidad del mercado del gas natural volverá a ser lo que fue hasta hace un año atrás". Historia de la ley, n. 20018.

109 "Ante esta realidad, la modificación legal propuesta responde a la necesidad de estabilizar los flujos de ingreso de los contratos de suministro a las compañías distribuidoras, de manera que, ocurra lo que ocurra con el actual mercado del gas suministrador, el suministro de electricidad esté disponible para el cliente regulado chileno. Es así como el objetivo primordial del proyecto es despejar la incertidumbre en el mercado eléctrico para el desarrollo de futuras inversiones en generación, restaurando y reforzando, de este modo, la seguridad tradicional de abastecimiento eléctrico para el país. Para ello es menester establecer estabilidad en el mecanismo de precios de abastecimiento del sector de clientes regulados, a objeto de garantizar que el proceso de inversiones se desarrolle con normalidad, como ocurría hasta antes de la actual situación del mercado del gas natural". Historia de la ley, n. 20018.

${ }^{110} \mathrm{CNE}$ (2017), p. 62.

${ }^{111}$ Art. 134, introducido por la Ley n. ${ }^{\circ} 20805$. 
de dichos cambios, en términos de producir un excesivo desequilibrio económico ${ }^{112}$ en las prestaciones mutuas del contrato respecto de las condiciones existentes al momento de la presentación de la oferta.

c. Inimputabilidad: la mayor onerosidad no puede resultar imputable al suministrador.

De esta forma, la Ley n. 20805 consagra expresamente el derecho de las generadoras de revisar los precios adjudicados y acordados con las distribuidoras, precisando los requisitos necesarios para que el contrato pueda ser modificado ${ }^{113}$. Como puede observarse, se trata de requisitos similares a los desarrollados por la teoría de la imprevisión.

\section{Técnicas empleadas \\ en contratos de suministro eléctrico no regulados}

Debido a la volatilidad inherente del mercado eléctrico, usualmente se establecen cláusulas en los contratos de suministro negociados de manera libre -entre generadoras y clientes libres- en virtud de las cuales se pueden reajustar sus términos de conformidad a las nuevas condiciones que lo afecten. En este sentido, y con relación al precio ${ }^{114}$, distinguiremos dos tipos de cláusulas que velan por mantener un equilibrio en las prestaciones del contrato: por un lado, las cláusulas de ajuste de precio, que se caracterizan por incorporar factores objetivos y calculables para modificar el precio bajo ciertas circunstancias que se contemplan expresamente y, por otro, las

${ }^{112}$ Conforme al inciso 4 del art. 134 de la Ley n. ${ }^{\circ} 20805$, se establecerán en las bases de licitación el porcentaje o variación mínima para determinar la magnitud que produzca el desequilibrio económico. En este sentido, en las bases de licitación de 2019 se señaló lo siguiente: "el precio de la energía podrá ser revisado únicamente en los casos que, por causas no imputables al Suministrador, los costos de capital o de operación para la ejecución del Contrato hayan variado en una magnitud tal que produzca un excesivo desequilibrio económico en las prestaciones mutuas del Contrato, respecto de las condiciones existentes en el momento de la presentación de la oferta, debido a cambios sustanciales y no transitorios en la normativa sectorial o tributaria, que tengan por efecto directo y demostrable una variación de más del $2 \%$ en los costos de capital o de operación para la ejecución del Contrato". Disponible en www.cne.cl/wp-content/uploads/2019/04/ Rex-Ex-CNE-273-2019-Bases-Licitaci\%C3\%B3n-Publica-2019-01.pdf [fecha de consulta: 2 de septiembre de 2019].

${ }^{113}$ Conforme a la ley, tanto la generadora como la distribuidora pueden activar el procedimiento para la revisión del precio por medio de una solicitud a la CNE. En caso de que no se llegue a un acuerdo en la audiencia citada al efecto, cualquiera de las partes del contrato en revisión podrá presentar su discrepancia ante el Panel de Expertos.

${ }^{114}$ También suelen pactarse cláusulas que ajustan o modifican otro tipo de condiciones diferentes al precio en el caso de ocurrir ciertos eventos, como cláusulas que permiten modificar los bloques (volúmenes) de suministro. 
cláusulas de revisión de precio o cláusulas hardship, que facultan a cualquiera de las partes a instar por una renegociación del contrato en el caso que se produzcan circunstancias imprevistas que afecten su economía.

Si bien estas dos categorías de cláusulas las podemos encontrar en muchos contratos de suministro, la lógica negocial que las subyace ha cambiado a partir de la entrada masiva de ERNC.

En efecto, como hemos visto más atrás, hasta antes del año 2015 la oferta de energía eléctrica era limitada, pues el mercado era controlado por pocas generadoras. En este contexto, el poder de negociación que tenían los clientes estaba reducido principalmente al volumen y plazo del suministro. No existía un gran margen para negociar los precios ofrecidos por las centrales ${ }^{115}$, y la posibilidad de ajustarlo o revisarlo durante la vigencia del contrato se establecía normalmente en favor de ellas. Así, a modo de ejemplo, las generadoras buscaban traspasarles a sus clientes (pass through) cualquier mayor costo de operación que se gatillase durante la ejecución del contrato de suministro, como podría ocurrir, por ejemplo, mediante la imposición de impuestos que graven la operación de centrales convencionales.

Sin embargo, a partir de la diversificación de la oferta de energía eléctrica y el aumento de la competencia entre las generadoras, los clientes libres han podido ir accediendo a condiciones cada vez más favorables en los contratos de suministro que suscriben, en concreto, han tenido mayor injerencia en la determinación del precio ${ }^{116}$. Su poder de negociación ha aumentado y un claro ejemplo de esta nueva dinámica se evidencia desde la gran migración de clientes regulados a libres (innovación introducida por la Ley n. $\left.{ }^{\circ} 20805\right)$. Solo en el año 2018 se experimentó un aumento del

115 "Por otra parte, el resultado de menor competencia en el mercado de los clientes libres es consistente con una conducta no-cooperativa, esto es, de competencia oligopolística o imperfecta. A diferencia de las licitaciones, mercado que se despejan vía negociaciones bilaterales sufren de fricciones y costes de búsquedas y de negociación que se debieran reflejar en mayores precios, en promedio", FABRA, MonTERIO y REGUANT (2013), p. 64.

116 "En un mercado de alta competencia, como es actualmente el de la generación eléctrica, la oportunidad es clara. Los clientes libres pueden beneficiarse de obtener, simultáneamente, condiciones de precios competitivos y de energía limpia. Hace tan solo unos años, esos objetivos parecían opuestos y resultaba prácticamente imposible conciliarlos en un contrato de suministro de energía eléctrica. Hoy en cambio, esos objetivos son coincidentes gracias al gran desarrollo del sector de las energías renovables y, en particular, de las denominadas Energías Renovables No Convencionales (ERNC), es decir, viento, sol, agua, biomasa, y geotermia", columna de opinión de Carlos Finat, director ejecutivo de Acera. Disponible en www.emb.cl/electroindustria/articulo.mvc?xid=3226\&xit=clienteslibres-y-energias-renovables [fecha de consulta: 2 de septiembre de 2019]. 
$163 \%$ en la cantidad de usuarios que migraron ${ }^{117}$ en búsqueda de precios más bajos en contratos negociados de forma directa con las generadoras ${ }^{118}$.

Esta nueva dinámica contractual ofrece una gran oportunidad a los clientes libres de incorporar cláusulas de ajuste o revisión de precios que, años atrás, se pactaban usualmente en beneficio exclusivo de las generadoras. Se trata de una posibilidad deseable desde una perspectiva de justicia conmutativa, sobre todo teniendo en consideración que la volatilidad del mercado eléctrico puede tanto beneficiar como perjudicar a todos sus participantes indistintamente.

\section{i. Cláusulas de ajuste de precio}

Las cláusulas de ajuste de precio permiten modificar el precio de la energía acordado al momento de la suscripción del PPA, a partir de la aplicación de ciertas reglas o parámetros que se acuerdan.

La cláusula de reajustabilidad o indexación es la más típica, en virtud de la cual "los montos del contrato se adecuan automáticamente a las circunstancias que lo rodean en su desarrollo" 119 , acordándose, además, la periodicidad del ajuste (e.g. trimestral, semestral, etc.). Por lo general, buscan modificar el precio de la energía conforme a la variación que experimenten los costos de los combustibles, del capital u otros costos 44 relevantes para la operación de la central. Dentro de estas cláusulas, las más recurrentes son las de indexación al IPC o al CPI (informado por el United States Bureau of Labour Statistics), o al precio del combustible empleado por la generadora con la que se suscribe el contrato (e.g. precio del petróleo diésel, crudo, carbón o del gas $\left.{ }^{120}\right)$.

${ }_{117}$ Artículo de prensa "Migración de clientes regulados a libres aumentó 163\% en 2018 y Enel lidera los traspasos". Disponible en www.revistaei.cl/2019/01/21/migracionclientes-regulados-libres-aumento-163-2018-enel-lidera-los-traspasos/ [fecha de consulta: 4 de septiembre de 2019].

118 "El éxodo en el último tiempo de estos clientes (principalmente de aquellos abastecidos por una empresa distribuidora), de un régimen de tarifa regulada a precio libre, ha obedecido a las mejores condiciones comerciales de suministro al que pueden optar hoy bajo la modalidad de cliente libre. Esto gracias al desafío competitivo que ha originado la masificación y creciente incorporación en nuestra matriz de fuentes de energía renovable, principalmente por la madurez tecnológica, de costos, y condiciones de contratación que han experimentado tecnologías como la solar fotovoltaica y la eólica", columna de opinión de Rodrigo Solís, director de estudios de generadoras de Chile. Disponible en www.emb. cl/electroindustria/articulo.mvc?xid=3227 [fecha de consulta: 2 de septiembre de 2019].

${ }^{119}$ GutiérRez (2002), p. 137.

${ }^{120}$ Véase, como referencia, las posibilidades de indexación que la CNE aprobó en las bases para la licitación del 2017, resolución exenta n. ${ }^{\circ} 42$, p. 98. Disponible en www.cne.cl/ wp-content/uploads/2016/12/Res-Ex-CNE-42-Aprueba-Bases-Licitaci\%C3\%B3n-2017-01. pdf [fecha de consulta: 2 de septiembre de 2019]. 
Otro tipo de cláusulas ${ }^{121}$ permiten ajustar el precio conforme a la fluctuación que experimente el costo marginal durante la vigencia del contrato, pues, como explicábamos más atrás, las generadoras deberán en primer término "retirar" la energía requerida por su cliente y pagar el costo marginal por ella, para solo después "venderla" al cliente al precio del contrato. Es por ello que, al momento de la celebración del PPA, por lo general se fija el precio en función de los costos marginales que se proyectan hacia el futuro.

Sin embargo, si los costos marginales varían en perjuicio de la generadora luego de la suscripción del contrato (i.e. cuando el precio spot sube y termina superando el precio contractual), se crea un evidente desequilibrio al ser más oneroso para la central suministrar la energía comprometida. Precisamente eso fue lo que ocurrió con la crisis del gas argentino, experiencia que incentivó la inclusión de cláusulas de ajuste de precio en caso de que los costos marginales excedieran ciertos límites ${ }^{122}$. De la misma forma, no deberían existir inconvenientes para que se acuerden cláusulas en el sentido opuesto, es decir, que autoricen reducir el precio de la energía en el evento que los costos marginales estén por debajo de ciertos niveles, pues, en tal caso, la generadora estaría enriqueciéndose por sobre lo que contemplaron las partes al fijar un precio en un contexto diverso.

Atendida la volatilidad del mercado eléctrico, es aconsejable que se pacten este tipo de cláusulas de modo de velar por un equilibrio en las prestaciones contractuales ${ }^{123}$. En definitiva, las partes querían obtener ese equilibrio mediante la celebración del contrato.

\section{ii. Cláusulas de revisión de precio}

De la misma forma, la diversificación de la oferta eléctrica viabiliza la estipulación de otro tipo de cláusulas que también apuntan a distribuir eficaz y equitativamente los riesgos del contrato ${ }^{124}$ frente a eventos que los puedan alterar: las cláusulas hardship. En este contexto, las partes al

121 También son usuales las cláusulas de fuerza mayor que habilitan, por ejemplo, a suspender o modificar los efectos del contrato (i.e. reemplazar el precio del contrato por el costo marginal) si la central no se encuentra operando por eventos imprevistos e irresistibles.

122 "Las diferencias entre el precio spot y el precio de los contratos de suministro impactan directamente en la viabilidad financiera de las empresas de generación. El riesgo del precio spot, particularmente después de la volatilidad que se creó producto de la crisis del gas argentino a mediados de la década pasada, llevó a que se extendiera la práctica de la indexación de precios de contratos a costo marginal”. SiKora et al. (2017), p. 4.

${ }^{123}$ Fueyo (1954), p. 121.

${ }^{124}$ Alguna parte de la doctrina lo ha llamado método analítico de redacción. RECART (2013), pp. 43-44. 
negociar sus PPA estarán en una posición más horizontal para resguardar sus intereses ante cambios en las circunstancias existentes al momento de contratar (como mandata la máxima del caveat emptor) ${ }^{125}$.

Si bien en un sentido amplio del término se puede afirmar que las cláusulas de ajuste de precio también caben dentro de esta categoría contractual -pues permiten modificar el contrato para mantener su conmutatividad frente a ciertas "dificultades"-, en un sentido más restringido las cláusulas hardship se diferencian en que

i) se asocian a circunstancias imprevistas, de modo que usualmente solo se contempla en el contrato el "tipo de evento" que pueda ocurrir (e.g. "cambios regulatorios") y

ii) genera efectos en el contrato que, por su relevancia (e.g. modificación, terminación, suspensión, negociación), requiere de un proceso más discernido para su determinación.

En este sentido, suele contemplarse un proceso de negociación previa en que las partes deben analizar si se han cumplido los requisitos para aplicar la cláusula ${ }^{126}$ (a diferencia de lo que ocurriría con aplicar simplemente la variación del CPI, si estuviéramos frente a una cláusula de ajuste de precio).

De esta forma, diremos que las cláusulas hardship son estipulaciones en virtud de las cuales las partes, frente a eventos imprevistos e inimputables que alteren el equilibrio económico del contrato sin hacer imposible su cumplimiento $^{127}$, se obligan a modificarlo, terminarlo o suspenderlo, de conformidad a los términos que se acuerden.

Por lo general se ha entendido, por el resabio de la teoría de la imprevisión, que las cláusulas hardship buscan anticipar el escenario donde una de las prestaciones se vuelve excesivamente onerosa de cumplir ${ }^{128}$. Por ejemplo, sumado a las nociones del art. 1467 del Código Civilitaliano, la Cámara Internacional de Comercio presentó un modelo de cláusula hardship en el año $2003^{129}$ que permite a las partes negociar la adaptación

${ }^{125}$ Por este motivo, se ha señalado que las Cortes no deberían intervenir cuando las partes pudieron protegerse mediante una cláusula hardship o de ajuste de precio. SimONE (2006), p. 77 y ss.

${ }^{126}$ BASCUÑán (2011).

${ }^{127}$ Guía Jurídica de CNUDMI para la Redacción de Contratos Internacionales de Construcción de instalaciones Industriales, 1988, p. 225; SÁNCHEz (2005), p. 1273.

${ }^{128}$ Böckstiegel (1985); Alterini (2002), p. 1 y ss.

129 "A party to a contract is bound to perform its contractual duties even if events have rendered performance more onerous than could reasonably have been anticipated the time of the conclusion of the contract.

Notwithstanding paragraph 1 of this Clause, where a party to a contract proves that:

(a) the continued performance of its contractual duties has become excessively onerous due to an event beyond its reasonable control which it could not reasonably have been expected to have taken into account at the time of the conclusion of the contract; and that. 
del contrato a las nuevas circunstancias más onerosas y, en caso de no prosperar, las habilita a solicitar la terminación del acuerdo ${ }^{130}$.

Sin embargo, a partir del ejercicio de la autonomía de la voluntad, la doctrina ha reconocido un concepto más amplio de cláusulas hardship cuando, no obstante la prestación no se ha vuelto estrictamente más onerosa para ninguna de las partes, la prestación que una de ellas debe cumplir se ha devaluado económicamente ${ }^{131}$. En este sentido, vemos que los Principios Unidroit sobre Contratación Comercial Internacional habilitan a las partes a renegociar el contrato frente a circunstancias que aumenten o disminuyen el costo de la prestación ${ }^{132}$.

Esta amplitud de las cláusulas de revisión permite recoger cualquier tipo de desequilibrio económico que sufra el contrato, extendiendo el

(b) it could not reasonably have avoided or overcome the event or its consequences, the parties are bound, within a reasonable time of the invocation of this Clause, to negotiate alternative contractual terms which reasonably allow for the consequences of the event.

Where paragraph 2 of this Clause applies, but where alternative contractual terms which reasonably allow for the consequences of the event are not agreed by the other party to the contract as provided in that paragraph, the party invoking this Clause is entitled to termination of the contract". Disponible en https://iccwbo.org/content/ uploads/sites/3/2017/02/ICC-Force-Majeure-Hardship-Clause.pdf [fecha de consulta: 17 de agosto de 2019].

${ }^{130}$ Una visión sobre las nuevas regulaciones que busca emitir la Cámara de Comercio Internacional a este respecto la encontramos en ERDEM (2018), p. 123 y ss.

${ }^{131}$ En definitiva, se busca restaurar el equilibrio económico del contrato, buscando que la correlación entre las prestaciones de las partes se resguarde a lo largo de su ejecución. Véase Castro y Zapata (2005), p. 4; Alterini (2002), p. 1; Simone (2006), p. 84. El propósito es entender, en palabras de Jorge López Santa María, "que las partes no son antagonistas sino que colaboradores asociados". SANTA María (2017), p. 325. "No toda dificultad hace procedente su aplicación, sino que una circunstancia sobreviniente que altera de manera efectiva el equilibrio de las prestaciones, ya porque el costo de una de ellas aumenta considerablemente de valor, ya porque el valor de la prestación que una de las partes recibe ha disminuido sustancialmente". CÁrdenas y Reveco (2018), p. 176. Además, la doctrina ha señalado que se produce un desequilibrio contractual "en aquellos casos en que el cumplimiento de la contraprestación ya no satisface el propósito previsto por las partes al momento de contratar". LóPEz (2015), p. 143.

${ }^{132} \mathrm{El}$ art. 6.2.1. dispone: "cuando el cumplimiento de un contrato llega a ser más oneroso para una de las partes, esa parte permanece obligada, no obstante, a cumplir sus obligaciones salvo lo previsto en las siguientes disposiciones sobre "excesiva onerosidad"”. Luego, el art. 6.2.2 define hardship cuando "el equilibrio del contrato es alterado de modo fundamental por el acontecimiento de ciertos eventos, bien porque el costo de la prestación a cargo de una de las partes se ha incrementado, o porque el valor de la prestación que un parte recibe ha disminuido, y; (a) dichos eventos acontecen o llegan a ser conocidos por la parte en desventaja después de la celebración del contrato; (b) los eventos no pudieron ser razonablemente tenidos en cuenta por la parte en desventaja en el momento de celebrarse el contrato; (c) los eventos escapan al control de la parte en desventaja; y (d) el riesgo de tales eventos no fue asumido por la parte en desventaja". Véase también SimONE (2006), p. 77 y ss. 
significado tradicional de lo que se entendía como más oneroso ya no solo circunscrito a la hipótesis en que se incrementan los costos de cumplir una obligación, sino, también, cuando dichos costos disminuyen (oscilación que, como hemos visto, es inherente al funcionamiento del mercado eléctrico). Esta visión se ajusta a la concepción conmutativa desde una doble perspectiva: jurídica, pues lo que "una de las partes se obliga a dar o hacer" puede dejar de ser equivalente a lo que "la otra parte debe dar o hacer a su vez" 133 tanto si el valor de una de las prestaciones sube o baja; y económica, por cuanto permite distribuir eficazmente los riesgos entre las partes atendido los bajos costos de transacción existente en este mercado de contratos ${ }^{134}$.

Las hipótesis que se regulan en las cláusulas hardship como "causas" de la excesiva onerosidad suelen ser diversas (e.g. políticas, económicas ${ }^{135}$. En contratos de suministro eléctrico se suelen incorporar, por su habitualidad y especial afectación a dichos contratos, cambios regulatorios que afecten la operación de las centrales.

En cuanto a sus efectos, se pueden regular distintas posibilidades, como la revisión del precio (o de otras cláusulas, como de volumen de suministro), suspensión ${ }^{136}$ y hasta la terminación del contrato. Normalmente, se contempla una etapa de "trato directo" o de negociaciones, y en caso de 48 fracaso, un mecanismo de resolución de disputas (arbitraje, por lo general). Sin embargo, como veremos a continuación, las partes deberían prestar especial atención a los requisitos que se exigirán para la procedencia de uno u otro efecto, atendidos los intereses jurídicos subyacentes en los PPA.

iii. Límites aconsejables a las cláusulas de ajuste o revisión de precios

Si bien las cláusulas de ajuste de precio y hardship permiten mantener la conmutatividad de los contratos de suministro eléctrico, durante su negociación las partes no deben olvidar otros intereses recíprocos que las motiva a suscribirlos, en especial cuando estamos frente a contratos de largo plazo.

${ }^{133}$ Art. 1441 del Código Civil.

134 "El análisis económico del derecho (AED de ahora en adelante) aporta una herramienta importante en las relaciones obligatorias cuando el tema es la eficiente asignación de riesgos y distribución de riquezas. Se parte, por ejemplo, del principio donde toda negociación tiene un costo de transacción, y cuando estos costos son bajos y pueden ser negociados, las partes lo harán libremente. Sin embargo, cuando los costos de transacción son muy altos, esto no será posible, y cabrá a la ley definir la asignación de los costos y riesgos para que se pueda establecer un sistema de compensación por los daños”, Monteiro (2013), pp. 89-90.

${ }^{135}$ Cardona (2011).

${ }^{136}$ Van Houtte (1993), pp. 10-11; AlCalde (2018), pp. 125-127. 
Por ejemplo, con relación a la negociación de cláusulas que habiliten el ajuste o revisión en favor de los clientes, se presenta un obstáculo no menor: chocan con el interés primordial que tienen las centrales a la hora de decidir comercializar su energía mediante contratos de largo plazo -en vez de hacerlo derechamente en el mercado spot-, este es, la certeza de que percibirán flujos estables durante cierto periodo. Si a este elemento añadimos el hecho de que muchos contratos de suministro se negocian en respaldo del financiamiento para la construcción de parques (project finance $^{137}$, la posibilidad de incluir este tipo de cláusulas se pone aún más cuesta arriba. En este sentido, la redacción genérica de una cláusula, tanto con relación a las causas que pueden gatillar la excesiva onerosidad o en cuanto a los efectos que el cliente pueda reclamar como consecuencia, puede derivar en una continua revisión del contrato en perjuicio de las generadoras, comprometiendo la estabilidad del suministro eléctrico.

En definitiva, los PPA son instrumentos que dan certidumbre jurídica y financiera a sus otorgantes. Tanto para las generadoras como para los clientes es un atractivo el desprenderse de la oscilación del mercado spot mediante la fijación de un precio de energía fijo y estable. Por ello, y para resguardar armónicamente este interés con la conmutatividad del contrato, se debería regular con especial detención

i) los niveles de variación que deben experimentar los costos marginales $\mathrm{y}$

ii) el transcurso de un tiempo mínimo en que dichos niveles se deben mantener para ajustar el precio.

Como hemos señalado, la variabilidad del mercado eléctrico constituye una característica inherente y, por tanto, conocida por las partes al momento de contratar, por lo que cierta magnitud de oscilación -i.e. de desequilibrio en las prestaciones- es esperable que sea tolerada y asumida por ellas como un riesgo bajo el contrato.

En la misma línea, los efectos que se derivan de la procedencia de las cláusulas de ajuste, y, especialmente, de las cláusulas hardship, deberían acordarse en función de la lógica que subyace a los PPA. Así, corresponde que la posibilidad de terminar el contrato como consecuencia de circunstancias imprevistas esté relacionada con hipótesis extremas que supongan el quebrantamiento definitivo de la economía del contrato, i.e. durante toda su vigencia.

137 "Contratos buscan asegurar que el proyecto reciba ingresos suficientes para cubrir un porcentaje de los costos de operación y de las obligaciones de deuda. Para desarrollos basados en Project Finance la firma de un contrato de suministro es esencial", SysteP (2013), p. 28. 


\section{Conclusiones}

El dinamismo y la variabilidad del mercado eléctrico chileno constituyen características propias y estructurales bajo las cuales los operadores del sistema desarrollan sus actividades de generación y comercialización. La evolución histórica del mercado spot y del mercado de contratos -regulados y libres- son la evidencia empírica de ello. Ahora bien, cuando estas oscilaciones se asocian a eventos impensados y disruptivos nace un campo amplio para la aplicación de la teoría de la imprevisión, cuya falta de reconocimiento legal expreso ha dado lugar a decisiones contradictorias por parte de nuestros tribunales, generando incertidumbre jurídica.

Frente a este contexto, la inclusión de cláusulas de ajuste y de revisión de precios -cláusulas hardship-en contratos de suministro eléctrico puede ser la solución, sobre todo considerando que las últimas transformaciones ocurridas en el mercado eléctrico propician una sofisticación en la redacción de este tipo de cláusulas, atendido el mayor poder de negociación de los clientes ante una diversificación de la oferta de energía.

Sin embargo, debido a los intereses que subyacen la suscripción de contratos de suministro eléctrico, las cláusulas de revisión deberían estar sujetas a una detallada redacción con relación a sus requisitos, especialmente

i) los eventos que la pueden gatillar,

ii) la magnitud del desequilibrio económico que se genera como consecuencia y

iii) los efectos que las partes pueden solicitar.

\section{Bibliografía CITADA}

Abeliuk, René (2003). Las obligaciones. $4^{\mathrm{a}}$ ed. Santiago: Editorial Jurídica de Chile, tomo 2.

Alcalde, Enrique (2007). "Corte de Apelaciones de Santiago y teoría de la imprevisión. Un hito fundamental en la evolución de nuestra justicia ordinaria”. Revista Chilena de Derecho, n. ${ }^{\circ} 34$. Santiago.

AlCALDE, Enrique (2018). La responsabilidad contractual. Causa y efectos de los contratos y sus obligaciones. Santiago: Ediciones Universidad Católica de Chile.

Alterini, Atilio (2002). "Teoría de la imprevisión y la cláusula de Hardship". Rivista di Diritto dell' integrazione e unificazione del diritto in Europa e in América Latina, vol. 13. Roma.

Arguello, Samuel (2012). "Comparación de Precios de Electricidad en Chile y países de la OCDE y América Latina”. Disponible en www.bcn.cl/obtienea rchivo?id=repositorio/10221/16020/1/Informe_Comision\%20Final_v4.doc [fecha de consulta: 3 de agosto de 2019]. 
Bahamondez, Felipe (2008). Fallo Gasatacama: El cambio de circunstancias en los contratos. Quo vadis?. Sentencias Destacadas 2008. Libertad y Desarrollo. Disponible en https://lyd.org/wp-content/uploads/2011/05/Libro-SentenciasDestacadas-2008-Digital.pdf [fecha de consulta: 10 de agosto de 2019].

Bascuñán, Felipe (2011). Los Contratos de Suministro Entre Generadoras y Clientes Libres. Adaptación de las condiciones comerciales, revisión de precios y terminación anticipada del contrato a la luz de la Ley $N^{0} 20.018$. VI Jornadas de Derecho Eléctrico, Actas de Derecho de Energía, n. ${ }^{\circ} 1-2011$, Santiago: Thomson Reuters.

Bloomberg Nef (2018). “Climatescope 2018”. Disponible en http://global-climatescope.org/assets/data/reports/climatescope-2018-report-en.pdf [fecha de consulta: 12 de agosto de 2019].

Böckstiegel, Karl-Heinz (1985). "Hardship, force majeure and special risks clauses in international contracts", in Norbert HoRn (ed.). Adaptation and Renegotiation of Contracts in International Trade and Finance. Holland: Kluwer.

CAPrile, Bruno (2007). “La imprevisión”. Actualidad Jurídica, n. ${ }^{15}$. Santiago.

CÁrdenas, Hugo y Ricardo Reveco (2018). Remedios contractuales. Cláusulas, acciones y otros mecanismos de tutela del crédito. Santiago: Thomson Reuters.

CARdona, John (2011). "Interpretación al interior de los Principios de Unidroit frente al Hardship”. Disponible en http://unidroitprinciples.blogspot.com/ 2011/04/clausulas-hardship-antecedentes.html [fecha de consulta: 7 de julio de 2019].

Castillo, Rodrigo (2017). "Los contratos de suministro de energía eléctrica; naturaleza y problemas en cláusulas arbitrales". Revista de Derecho Administrativo Económico, n. ${ }^{\circ} 24$. Santiago.

Castro, Ana María, Ana Cecilia Zapata (2005). "La cláusula de hardship en los contratos internacionales". Revist@e-mercatoria. Vol. 4, n.⒉ Bogotá.

CDEC-SING (2015). Efectos Técnico-Económicos de la Integración de Energía Eólica y Solar en el SING: Escenario año 2017. Disponible en http://cdec2.cdec-sing. cl/pls/portal/cdec.pck_pag_web_pub.get_file?p_file=Estudio_ERNC_2015. pdf [fecha de consulta: 1 de junio de 2019].

Clerc, Jacques, Juan Carlos Olmedo, Jaime Peralta, María Luisa SaAvedra, Enzo Sauma, Ignacio Urzúa, Andrés Hernando (2017). Energías renovables en Chile. Hacia una inserción eficiente en la matriz eléctrica. Disponible en www. cepchile.cl/cep/site/docs/20180124/20180124191509/libro_energia_cep.pdf [fecha de consulta: 2 de julio de 2019].

CNE (2017). Nueva Ley Chilena de Licitaciones de Suministro Eléctrico para Clientes Regulados: un caso de Éxito. Disponible en www.cne.cl/wp-content/ uploads/2017/08/Libro-Licitaciones-de-Suministro-Eléctrico.pdf [fecha de consulta: 2 de junio de 2019].

CNE (2018). Anuario Estadístico de Energía. Disponible en www.cne.cl/wp-content/ uploads/2019/04/Anuario-CNE-2018.pdf [fecha de consulta: 6 de agosto de 2019]. 
Corral, Hernán (2010). Contratos y daños por incumplimiento. Santiago: Abeledo Perrot-Legal Publishing.

De la Maza, Lorenzo (2009). "La teoría de la imprevisión”, en Raúl Tavolari (coord.). Obligaciones. Santiago: Editorial Jurídica de Chile. Tomo I.

Dörr Zegers, Juan Carlos (1988). "Notas acerca de la teoría de la imprevisión”. Revista Chilena de Derecho, vol. 12. Santiago.

Erdem, Ercüment (2018). "Revision of the ICC Force Majeure and Hardship Clause. Hardship and Force Majeure in International Commercial Contracts: Dealing with Unforeseen Events in a Changing World”. Dossiers of the ICC Institute of World Business Law, vol. 17. Kluwer Law International.

Evans, Eugenio, Eduardo YañEz (2017). Derecho y regulación económica de la energía eléctrica. Santiago: Thomson Reuters.

Fabra, Natalia, Juan-Pablo Montero, Mar Reguant (2013). La competencia en el mercado eléctrico mayorista en Chile. Disponible en www.fne.gob.cl/wpcontent/ uploads/2013/11/Montero_fabra.pdf [fecha de consulta: 7 de agosto de 2019].

FuEyo, Fernando (1954). "Algo sobre la teoría de la imprevisión”. Revista de Derecho y Jurisprudencia, n. ${ }^{\circ}$ 1, tomo 51. Santiago.

Galetovic, Alexander, Cristián Muñoz (2008). "Energías Renovables No Convencionales: ¿Cuánto nos van a costar?”. Disponible en www.cepchile.cl/cep/ site/docs/20160304/20160304094738/r112_agaletovic_EnergiaRenovables. pdf [fecha de consulta: 7 de julio de 2019].

GatiCA, Diego (2017). Mercado eléctrico y generadores de ERNC: análisis de las leyes $n^{\circ} 20.805$ y $n^{\circ} 20.936$, tesis para optar al grado de Licenciado en Ciencias Jurídicas y Sociales, Universidad de Chile, Facultad de Derecho. Disponible en http://repositorio.uchile.cl/bitstream/handle/2250/146823/Mercado el $\%$ C3\%A9ctrico-y-generadores-de-ERNC-an $\%$ C3\%A1lisis-de-las LeyesNo-20.805-y-No 20.936.PDF?sequence=1\&isAllowed=y [fecha de consulta: 7 de julio de 2019].

González, Aldo e Isidora Palma (2017). "Impacto de la reforma del 2014 en las subastas de electricidad en Chile". Texto inédito elaborado para la CNE.

Gordley, James, Arthur von Mehren (2006). An Introduction to the Study of Comparative Law, Reading, Cases and Materials. Cambrigde: Cambridge University Press.

Gutiérrez, Paulina (2002). El contrato de suministro de energía eléctrica a clientes libres. Tesis para optar al grado de Licenciado en Ciencias Jurídicas y Sociales. Santiago: Universidad de Chile, Facultad de Derecho. Disponible en http://repositorio.uchile.cl/bitstream/handle/2250/107348/de gutierrez_p. pdf?sequence $=3$ [fecha de consulta: 12 de julio de 2019].

IEA (2015). World Energy Outlook 2015. Disponible en www.iea.org/publications/freepublications/publication/WEO2015.pdf [fecha de consulta: 9 de julio de 2019].

Illanes, Claudio (2000). Posición personal sobre la teoría de la imprevisión en la legislación chilena. Estudios sobre reformas al Código Civil y Código de Comercio. Santiago: Editorial Jurídica de Chile. 
Irena (2017). Renewable Energy Auctions. Disponible en www.irena.org/-/media/ Files/IRENA/Agency/Publication/2017/Jun/IRENA_Renewable_Energy_Auctions_2017.pdf [fecha de consulta: 7 de julio de 2019].

Irena (2018). Renewable Power Generation Costs in 2018. Disponible en www. irena.org/-/media/Files/IRENA/Agency/Publication/2019/May/IRENA_Renewable-Power-Generations-Costs-in-2018.pdf [fecha de consulta: 7 de julio de 2019].

LAZARD (2018). "Lazard's Levelized Cost of Energy Analysis - Version 12.0". Disponible en www.lazard.com/media/450784/lazards-levelized-cost-ofenergy-version-120-vfinal.pdf [fecha de consulta: 9 de julio de 2019].

López, Patricia (2015). "El principio de equilibrio contractual en el código civil chileno y su particular importancia como fundamento de algunas instituciones del moderno derecho de las obligaciones en la dogmática nacional". Revista Chilena de Derecho Privado, n. ${ }^{\circ}$ 25. Santiago.

Momberg, Rodrigo (2008). Análisis crítico desde el derecho alemán y nacional de la sentencia de la Corte de Apelaciones de Santiago que acoge la teoría de la imprevisión. Estudios de Derecho Civil III. Santiago: Legal Publishing.

Momberg, Rodrigo (2010a). "La revisión del contrato por las partes: el deber de renegociación como efecto de la excesiva onerosidad sobreviniente". Revista Chilena de Derecho, vol. 37, n. ${ }^{\circ}$. Santiago.

Momberg, Rodrigo (2010b). "Teoría de la imprevisión: la necesidad de su regulación legal en Chile”. Revista Chilena de Derecho Privado, n. ${ }^{\circ}$ 15. Santiago.

MOMBERG, Rodrigo (2011). The effect of a change of circumstances on the binding force of contracts. Comparative perspectives. Utrecht: University of Utrecht.

Monteiro, Rodrigo (2013). "El interés económico de las partes y el incumplimiento contractual". Revista de Derechos Fundamentales de laUniversidad de Viña del Mar, n. ${ }^{\circ} 10$. Viña del Mar.

Peñallillo, Daniel (2000). "La revisión judicial de obligaciones y contratos en la reforma del Código Civil (La lesión y la imprevisión)". Revista de Derecho de la Universidad de Concepción, n. ${ }^{\circ}$ 208. Concepción.

Puig, Federico (1976). Compendio de Derecho Civil Español. $3^{\mathrm{a}}$ ed. Madrid: Ediciones Pirámide S.A., vol. 3.

RAINERI, Ricardo (2018). Transición energética en Chile: una verdad incómoda, documento de trabajo n. ${ }^{\circ} 39$. Santiago: Centro Latinoamericano de Políticas Económicas y Sociales de la Universidad Católica. Disponible en www.clapesuc.cl/assets/ uploads/2018/01/05-01-18-doc-trab-39-r-raineri-transicin-energtica-en-chileuna-verdad-incmoda-dec-9-2017.pdf [fecha de consulta: 18 de junio de 2019].

RECART, Joaquín (2013). Incumplimiento de declaraciones y garantías contractuales. Tesis para optar al grado de Magister en Derecho. Santiago: Universidad de Chile.

Rozas, Rodrigo (2016). Análisis expost del efecto de la ley corta II $n^{\circ} 20.018$ en los precios de los contratos de suministro de largo plazo de las distribuidoras. Tesis para optar al grado de Magister en Economía Energética, Universidad Técnica 
Federico Santa María. Disponible en https://repositorio.usm.cl/bitstream/ha ndle/11673/23301/3560900232297UTFSM.pdf?sequence=1\&isAllowed=y [fecha de consulta: 7 de julio de 2019].

RudNick, Hugh (2011). "Las tecnologías de energías renovables y su impacto en el marco regulatorio". V Foro Latinoamericano sobre Seguridad Energética, Crecimiento Sostenible e Integración Regional, Santiago. Disponible en www. systep.cl/documents/CIER\%20Noviembre2011\%20Rudnick.pdf [fecha de consulta: 2 de agosto de 2019].

SAnta María, Jorge (2017). Los contratos. Parte general. $6^{\mathrm{a}}$ ed. Santiago: Editorial Jurídica de Chile.

Sikora, Iryna, Juan CAmpos, Javier Bustos (2017). "Determinantes del precio spot eléctrico en el sistema interconectado central de Chile". Revista de Análisis Económico, vol. 32, n. ${ }^{\circ}$ 2. Santiago.

Simone, Amalia (2006). "El hardship en la contratación comercial internacional". Revista de Derecho, n. ${ }^{\circ}$. Quito.

SÁnchez, Sixto (2005). "Hardship en la contratación internacional: Principios comunes para una unificación desde el Derecho comparado", en Marina Vargas Gómez-Urrutia, Ana Salinas de Frías; Juan Antonio Carrillo SAlCEDo (coords.). Soberanía del Estado y Derecho Internacional (homenaje al profesor Juan Antonio Carrillo Salcedo). Sevilla: Servicios de Publicaciones de las Universidades de Córdoba, Sevilla y Málaga. 2005. Vol. 2.

SysteP (2012). ¿ ¿stamos hipotecando nuestro futuro? Efectos de la incertidumbre en el mercado eléctrico. Disponible en www.systep.cl/documents/Mocarquer $\% 20 X I I \% 20 J$ ornadas\%20de \%20Derecho\%202012.pdf [fecha de consulta: 2 de agosto de 2019].

Systep (2013). "Contrato de generación de electricidad: motor de expansión de capacidad". Disponible en www.systep.cl/documents/S.\%20Mocarquer-Contratos\%20de\%20energia-30102013.pdf [fecha de consulta: 18 de julio de 2019].

SysteP (2016a). "Proyección del costo marginal y comercialización de la energía: desafíos para la minihidro". Disponible en www.systep.cl/documents/Rudnick_APEMEC_290616.pdf [fecha de consulta: 18 de julio de 2019].

Systep (2016b). "Reporte mensual del sector eléctrico". Disponible en www.systep. cl/documents/reportes/112016_Systep_Reporte_Sector_Electrico.pdf [fecha de consulta: 2 de agosto de 2019].

Systep (2017). "Impacto de energías variables en el sistema eléctrico chileno". Disponible en www.systep.cl/documents/ClusterEnergiaBiobio101017f [fecha de consulta: 26 de julio de 2019].

Systep (2018). "Los precios de nudo en el mercado eléctrico chileno". Disponible en www.systep.cl/documents/SenalesEspaciales\%20HRudnick [fecha de consulta: 2 de agosto de 2019].

Van Houtte, Hans (1993). "Changed Circumstances and Pacta Sunt Servanda", in Emmanuel GAILLARD (ed.). Transnational Rules in International Commerce and Arbitration. Paris: ICC Publishing. 
Zimmermann, Reinhard (1990). The Law of Obligations: Roman Foundations of the Civilian Tradition. Cape Town: Oxford University Press.

SigLAS Y ABREVIATURAS

al. alii (otros)

art. artículo

arts. artículos

$\mathrm{c} /$ a veces c. con

CDEC Centro de Despacho Económico de Carga

CNE Comisión Nacional de Energía

CNUDMI Comisión delas Naciones Unidas para el Derecho Mercantil

CPI o IPC Consumer Price Index

coord. coordinador

CVNC Costo Variable No Combustibleee-

ed. edición $a$ veces editor

eds. editores

e.g. exempli gratia

EIA Energy Information Administration

EMOS Empresa Metropolitana de Obras Sanitarias

Endesa Empresa Nacional de Electricidad

Enel Ente nazionale per l'energia elettrica

ERNC energías renovables no convencionales

GWh Gigawatt hora

hrs. horas

html HyperText Markup Language

http Hypertext Transfer Protocol

https Hypertext Transfer Protocol Secure

Ibid. Ibidem

i.e. id est

IEA International Energy Agency

inc. inciso

Irena International Renewable Energy Agency

KW Kilowatt

LGSE Ley General de Servicios Eléctricos

MW Megawatt 
MWh Megawatt hora

n. ${ }^{\circ}$ número

OCDE Organización para la Cooperación y el Desarrollo Económicos

op. cit. opere citato (obra citada)

p. página

pp. páginas

PPA power purchase agreement

S.A. sociedad anónima

SIC Sistema Interconectado Central de Chile

SING Sistema Interconectado del Norte Grande

ss. siguientes

ter. tres veces

Unidroit Instituto Internacional para la Unificación del Derecho Privado

USD a veces US\$ Dólares estadounidenses

UTM Unidad Tributaria Mensual

vol. volumen

www World Wide Web 